\title{
Sand transport under combined current and wave conditions: A semi-unsteady, practical model
}

\author{
Paulo Alves da Silva ${ }^{\mathrm{a}, *}$, André Temperville ${ }^{\mathrm{b}}$, Fernando Seabra Santos ${ }^{\mathrm{c}}$ \\ a Department of Physics, University of Aveiro, 3810-193 Aveiro, Portugal \\ b Laboratoire des Ecoulements Géophysiques et Industriels, B.P.53, 38041 Grenoble Cedex 9, France \\ ${ }^{\mathrm{c}}$ Department of Civil Engineering, University of Coimbra, 3049 Coimbra Codex, Portugal
}

Received 17 March 2005; received in revised form 31 May 2006; accepted 1 June 2006

Available online 9 August 2006

\begin{abstract}
For the general purposes of morphodynamic computations in coastal zones, simple formula-based models are usually employed to evaluate sediment transport. Sediment transport rates are computed as a function of the bottom shear stress or the near bed flow velocity and it is generally assumed that the sediment particles react immediately to changes in flow conditions. It has been recognized, through recent laboratory experiments in both rippled and plane bed sheet flow conditions that sediment reacts to the flow in a complex manner, involving non-steady processes resulting from memory and settling/entrainment delay effects. These processes may be important in the cross-shore direction, where sediment transport is mainly caused by the oscillatory motions induced by surface short gravity waves.

The aim of the present work is to develop a semi-unsteady, practical model, to predict the total (bed load and suspended load) sediment transport rates in wave or combined wave-current flow conditions that are characteristic of the coastal zone. The unsteady effects are reproduced indirectly by taking into account the delayed settling of sediment particles. The net sediment transport rates are computed from the total bottom shear stress and the model takes into account the velocity and acceleration asymmetries of the waves as they propagate towards the shore.

A comparison has been carried out between the computed net sediment transport rates with a large data set of experimental results for different flow conditions (wave-current flows, purely oscillatory flow, skewed waves and steady currents) in different regimes (plane bed and rippled bed) with fine, medium and coarse uniform sand. The numerical results obtained are reasonably accurate within a factor of 2 . Based on this analysis, the limits and validity of the present formulation are discussed.
\end{abstract}

(C) 2006 Elsevier B.V. All rights reserved.

Keywords: Sediment transport models; Phase lags; Sheet flow; Ripples; Skewed waves

\section{Introduction}

Studies on sediment transport are currently one of the main issues in the marine coastal environment. Over the last decades, along many parts of the coast, a general retreat of the shoreline associated with beach erosion is being observed. These morphological changes are often induced by changes in the sediment supply, caused by the construction of river dams, by the destruction of natural protections, such as dune systems, and

\footnotetext{
* Corresponding author. Fax: +351 234424965.

E-mail addresses: psilva@fis.ua.pt (P.A.da Silva), andre.temperville@hmg.inpg.fr (A. Temperville),fseabra@dec.uc.pt (F. Seabra Santos).
}

due to modifications in the wave field and mean sea level caused by global climate changes. Beach erosion problems have been tackled by engineering projects such as those based on the construction of seawalls and groynes. It is currently believed that these kind of solutions solve the problem locally but do not avoid, and may in some cases intensify, the erosion effects at some neighbouring places. Beach nourishment projects are a more natural solution to beach erosion problems, but these require a continuous supply of sediment. Sand mining taking place on the inner continental shelf, designed to nourish beaches and coastal dunes, may also have a negative environmental impact if it induces near shore coastal erosion. Furthermore, marine sediment can be a carrier of pollutant substances and therefore might affect the ecology of the coastal environment. 
The numerical simulation of hydrodynamic and sediment transport processes form a powerful tool in the description and prediction of morphological changes and sediment budgets in the coastal zone. One of the key elements in a morphodynamic model is the correct quantification of local sand transport. Due to the complexity of the processes that intervene in sediment transport (e.g., mobile bed effects, sediment-flow interactions) and also due to the difficulties of making accurate in situ measurements (velocities and sediment concentrations) near the bed, sand transport models still have a strong empirical component. As stated in Davies et al. (2002), field measurements are a necessary requirement to carry out model validation and to achieve higher accuracy predictions of sand transport rates. The need for reliable and more accurate sand transport models has impelled experimental and theoretical studies, such as the ones carried out in the recent MASTII G8-M, SEDMOC and SANDPIT projects supported by the EU.

Different model concepts are presently being used in order to predict sediment transport in coastal zones, i.e., in wave or combined wave-current flow conditions. These range from the empirical or theoretical transport formulas (e.g., quasi-steady and semi-unsteady models) to more sophisticated bottom boundary layer models (see Soulsby, 1997; Davies et al., 2002, for a review).

Quasi-steady models (e.g., Bailard, 1981; Ribberink, 1998) assume that sand transport reacts immediately to changes in flow conditions: the sediment transport is computed as a function of bottom shear stress or the near bed velocity. The processes related to flow unsteadiness (e.g., memory, entrainment and settling delay effects) are not accounted for within this kind of model. Therefore, the quasi-steady approach is only suitable to use in conditions where the sediment is confined to a thin layer near the bottom such that the settling time of the sediment particles is much smaller than the wave period. In spite of these limitations, the proposed formula of Ribberink (1998), based on the well-know Meyer-Peter and Müller formula, responds well for a wide range of oscillatory and steady flows in flat bed conditions (sheet flow) for median grain diameters, $d_{50}$, greater than $0.2 \mathrm{~mm}$ (medium and coarse sand).

When a large amount of sediment remains in suspension through the wave cycle, as is the case in rippled beds or in wave breaking conditions, the quasi-steady approach is not suitable. The presence of unsteady effects in sediment transport was evident in Watanabe and Isobe (1990) rippled bed experiments. They show evidence that, in some conditions, an oscillatory flow over a rippled bed produces sediment transport in the opposite direction of the mean current. These effects are due to the vortices formed over a ripple that retain the sediments entrained from the bed. There is also experimental evidence that indicates that the unsteady effects are important for fine/very fine sands in sheet flow plane bed conditions (Dibajnia and Watanabe, 1992; Ribberink and Chen, 1993; Janssen and Riberrink, 1996; Ahmed and Sato, 2003; O'Donoghue and Wright, 2004). Dibajnia and Watanabe (1992) have conducted a series of experiments under asymmetric oscillations with short wave periods and superimposed currents with a median sediment grain size of $0.2 \mathrm{~mm}$. They found that the quasi-steady transport model of Madsen and Grant (1976) fails to predict the magnitude and direction of the net measured transport rates because the transport at successive half cycles of oscillations are not independent of each other. In the Ribberink and Chen (1993) experiments, made with regular asymmetric 2 nd order Stokes waves and $d_{50}=0.13 \mathrm{~mm}$, the observed net sediment transport during the wave cycle was in the opposite direction of the waves for root mean square values of the orbital velocity greater than $0.7 \mathrm{~m} / \mathrm{s}$. In the Janssen and Riberrink (1996) experiments (see also Dohmen-Janssen, 1999), made with sinus waves and collinear currents with a $0.13 \mathrm{~mm}$ median grain diameter, the net sediment transport during the wave cycle decreased with a decreasing wave period. Furthermore, the net transport rates obtained with this fine sediment were, with the same hydrodynamic conditions, smaller than the rates obtained with coarser sediments $\left(d_{50}=0.21\right.$ and $\left.0.32 \mathrm{~mm}\right)$. The experiments of Ahmed and Sato (2003) with uniform sediments $\left(d_{50}=0.21 \mathrm{~mm}\right)$ under asymmetric oscillatory flow (first-order cnoidal waves), show that in the high velocity regime there is an offshore net transport. Moreover, O'Donoghue and Wright (2004) have performed a series of experiments with 2 nd order Stokes waves. The time-dependent sand flux profiles clearly illustrate the unsteady effects in the case of fine sands (see Figs. 9 and 10 therein). The quasi-steady models are not able to accurately reflect these experimental results.

Nielsen (1992) discussed different model concepts to predict sediment transport over rippled beds (e.g., the grab-and-dump model). Dibajnia and Watanabe (1992) have proposed a model that takes into account the time lag between the suspended sediment particles and the flow. This is done by an exchange of sediment flux between the two half cycles in a wave period caused by a delayed settling of sediment particles. Further developments of this model (e.g., Dibajnia, 1995; Dibajnia and Watanabe, 1996, 1998, 2001; Ahmed and Sato, 2003; Watanabe and Sato, 2004) have considered the same description of the unsteady effects. Dohmen-Janssen (1999) (see also DohmenJanssen et al., 2002) proposed an extension of Ribberink's model, where an analytical diffusion model for sediment concentration (based on Nielsen, 1979) is used for modelling the phase lag effects. It should be noted that Dohmen-Janssen introduces in her model a correction parameter to Ribberink's model, which modifies the magnitude of the net sediment transport rate, but not its direction. Therefore, a priori, this model cannot simulate accurately situations where the unsteady effects invert the direction of the net transport. Although these semi-unsteady models do not describe the vertical distribution of the flow and sediment concentration, it is evident that they overcome some deficiencies of the quasi-steady models particularly in the case where non-steady conditions prevail in the sediment transport process (e.g., rippled beds, high orbital velocities and fine sediments: $d_{50} \leq 0.2 \mathrm{~mm}$ ).

Over the last two decades boundary layer models that describe the intra-wave structure of the flow and sediment distribution over plane and rippled beds have been developed. These complex mathematical models involving high order turbulence closure schemes numerically solve the momentum equations and the sediment balance equation in the wave or combined 
wave-current bottom boundary layer. The instantaneous sediment transport rate is computed by vertically integrating the sediment fluxes obtained at each level. The main reason for developing these models is to describe and understand the physical processes that occur in the bottom boundary layer and so that they can serve as reference models to test the more simple parametric formulas. Davies et al. (1997) present a comparison of different 1DV models suitable for sheet flow conditions (plane beds), which were developed within the MASTII G8-M. The numerical solutions were compared with experimental results obtained in the WL| Delft Hydraulics oscillating water tunnel with a median sediment grain size equal to $0.2 \mathrm{~mm}$ (Katopodi et al., 1994). Although the results concerning the total sediment transport agree reasonably well with the experimental data, there are some limitations shared by all the models: a) the computed mean values of sediment concentration in the sheet flow layer over the wave cycle are lower than the experimental ones; b) none of the models are able to reproduce the pick-up events of sediment at the flow reversal that occur in some experimental conditions; c) in the upper layers of the boundary layer there is a phase lag between the computed and measured sediment concentration.

In the case of fine sediments, the numerical results obtained by Silva (2001) with the 1DV model of Huynh Thanh et al. (1994), show that the limitations pointed out above are critical to the sediment flux, which results in an overestimation of the total transport. The works of Savioli and Justesen (1997), Guizien et al. (2001), Silva (2001) and Guizien et al. (2003) have shown that it is possible to improve the description of the sediment concentration within the sheet flow layer. Damgaard et al. (2001) have made a comparison of semi empirical and bottom boundary layer models for selected practical cases and concluded that the more sophisticated models have not done as well as the relatively simple methods as they became more volatile throughout the relevant parameter range.

The aim of the present work is to develop a practical model that is able to predict the total net sediment transport rate in different flow conditions that are characteristic of the coastal zones. Here, the flow can be thought of as being composed of an irregular wave field superimposed to a steady flow (e.g., tidal and wind induced currents, longshore wave currents and undertow). Therefore, the model should not only be able to describe sediment transport in steady flow dominant conditions but also when the wave orbital velocity is dominant in the transport processes. The model should also take into account the wave velocity asymmetry (high narrow crest with a shallow wide trough, as in 2nd order Stokes waves and cnoidal waves) and the asymmetric acceleration of the waves (as in sawtooth waves). These are related to the skewness of fluid velocity $\left(\overline{u^{3}}>0\right)$ and acceleration $\left(\frac{\overline{\mathrm{d} u^{3}}}{\mathrm{~d} t}>0\right)$, respectively, and are recognized (Ribberink and Al-Salem, 1994; King, 1991; Elgar et al., 2001; Watanabe and Sato, 2004), as important factors that affect both the magnitude and the direction of sediment transport as the waves move towards the beach and in the breaking zone. The numerical results should be accurate when compared with experimental results, i.e., within a factor of 2 (factor of 2 means between 2 and 0.5 times the actual transport), and the model should be simple enough to be easily included in complex morphodynamic models.

The practical model presented has been based on the original ideas of Dibajnia and Watanabe (1992) (herein after referred to as D\&W). Silva et al. (2001) have shown that the D\&W model presents some shortcomings, namely, that the performance of the formula depends on sediment size and there is a discontinuity in the formula results concerning the limiting case of a steady current. A new version of that model was proposed. Further developments of the model included its application to several data sets, concerning wave-current flows (collinear and non-collinear), steady flows and asymmetric waves (see Silva et al., 2001, 2005). This research has led to the development of a new semi-unsteady model as presented below.

In Section 2, we present a review of the $\mathrm{D} \& \mathrm{~W}$ model and extend the formulation to the case of non-collinear wave-current flows and steady currents. In Section 3, the parameters of the model equations are set for a sinus wave, a 2 nd order Stokes wave and a sawtooth wave. A comparison of D\&W model results with a large experimental data set is made in Section 4. The reliability and limitations of this model are analysed. In Section 5 , we propose a new practical model which improves the description of the experimental results. It is shown that in order to achieve consistent numerical results, the new formulation has to take into account the bed shear stress. Section 6 presents the results obtained when the new formulation is applied to regular and irregular skewed waves.

\section{A review of Dibajnia and Watanabe model with an extension to non-collinear wave-current and steady flows}

\subsection{Collinear wave-current flows}

Consider the flow condition where a train of waves propagates to the shore in the presence of a collinear steady current with mean velocity $U_{0}$. As depicted in Fig. 1, for each individual wave, we can distinguish a positive and a negative half cycle of the near bed velocity, $u(t)$, with time duration $T_{c}$ and $T_{t}$, respectively (the indices $c$ stands for the crest and $t$ for the trough).

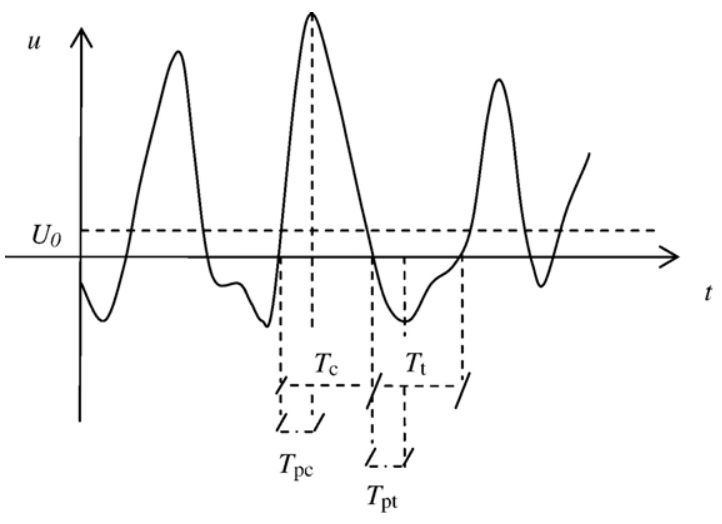

Fig. 1. Near bed time velocity series. 
For each one of these half cycles, we can define an equivalent sinusoidal velocity amplitude, $u_{c}$ and $u_{t}$ as:

$u_{c}^{2}=\frac{2}{T_{c}} \int_{0}^{T_{c}} u^{2}(t) \mathrm{d} t \quad u_{t}^{2}=\frac{2}{T_{t}} \int_{T_{c}}^{T} u^{2}(t) \mathrm{d} t$

$u_{c}, u_{t}, T_{c}$ and $T_{t}$ are the characteristic variables of the model. The total net sediment transport rate during the wave period, $q_{s}$, is computed according to:

$\frac{q_{s}}{w_{0} d_{50}}=\alpha|\Gamma|^{\beta} \frac{\Gamma}{|\Gamma|}$

where $\alpha$ and $\beta$ are two empirical constants, $w_{0}$ represents in the D\&W model the sediment fall velocity, $w_{s}$, and $\Gamma$ is calculated using the following equation:

$\Gamma=\frac{u_{c} T_{c}\left(\Omega_{t}^{3}+\Omega_{t}^{\prime 3}\right)-u_{t} T_{t}\left(\Omega_{t}^{3}+\Omega_{c}^{\prime 3}\right)}{\left(u_{c}+u_{t}\right) T}$

According to Eqs. (2) and (3) the net transport rate, $q_{s}$, is computed by working out the difference between the sediment transported during the positive half cycle and the negative half cycle. In Eq. (3) the quantities $\Omega_{i}$ and $\Omega^{\prime}{ }_{i}(i=c, t)$ represent, respectively, the amount of sediment which are entrained, transported and settled in the $i$ half cycle, and the amount of sediment still in suspension from the $i$ half cycle, which will be transported in the next half cycle. The non-steady processes are taken into account through the exchange of sediment fluxes between the two half cycles ( $\Omega_{i}^{\prime}$ quantities). This exchange mechanism is controlled in the model by a parameter $\omega_{i,}$, defined for each half cycle, which depends on the ratio between the settling time of the sediment particles, $T_{\text {fall }}$, and the duration of each half cycle, $T_{i}$ :

$\omega_{i}=\frac{T_{\text {fall }}}{T_{i}}=\frac{\Delta_{\mathrm{s}} / w_{s}}{T_{i}}=\frac{1}{2} \frac{\mathrm{u}_{i}^{2}}{(s-1) g T_{i} w_{s}}$

In the last equation, $\Delta_{s}$ represents the height to which a particle is entrained into the flow, $g$ being the gravity acceleration and $s$ the relative density $\left(s=\rho_{s} / \rho\right.$, with $\rho_{s}$ the density of sediment). Dibajnia and Watanabe (1992) argue that $\Delta_{\mathrm{s}}$ can be calculated

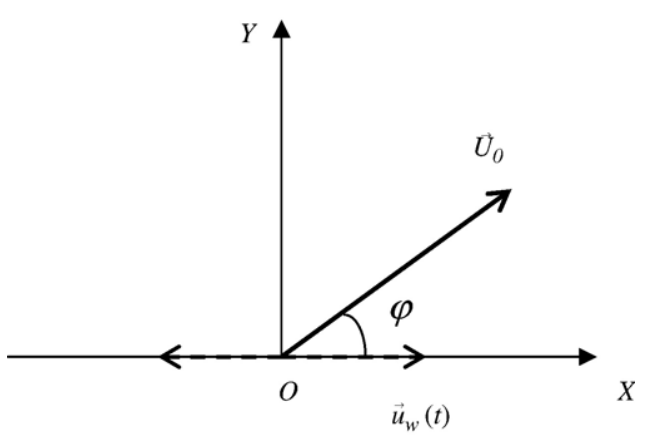

Fig. 2. Oblique wave-current flow illustrating the wave and current vector velocities. assuming that the flow kinetic energy is transferred to the required potential energy to rise up sand. This is a rather critical point, because turbulent kinetic energy dissipation is not taken into account. This issue will be analysed more closely in Section 5 . When the value of $\omega_{i}$ exceeds a threshold limiting value, $\omega_{c r}$, part of the sediment that is entrained during the $i$ half cycle remains in suspension and is carried into the opposite direction by the velocity of the succeeding cycle. Therefore, this mechanism may enhance or reduce the transport rate in the wave direction. According to Eq. (4), large values of $\omega_{i}$ can be expected to be found for higher orbital velocities, fine sediment (small sediment fall velocities) and small wave periods.

In Eq. (3), the quantities $\Omega_{i}$ and $\Omega_{i}^{\prime}$ are calculated as:

$\Omega_{i}=\Psi_{i} \min \left(1, \frac{\omega_{\mathrm{cr}}}{\omega_{i}}\right) \quad \Omega_{i}^{\prime}=\Psi_{i} \max \left(0,1-\frac{\omega_{\mathrm{cr}}}{\omega_{i}}\right)$

where $\Psi_{i}$ represents an equivalent mobility number:

$\Psi_{i}=\frac{\mathrm{u}_{i}^{2}}{(s-1) g d_{50}}$

It should be noted that the value of $\Omega_{i}$ when $\omega_{i}>\omega_{\mathrm{cr}}$ is a saturated value. Based on experimental results corresponding to sheet flow conditions and with a median grain diameter of $0.2 \mathrm{~mm}$, Dibajnia and Watanabe (1992) proposed $\omega_{\mathrm{cr}}=1$, and the values of the constants $\alpha$ and $\beta$ equal to 0.001 and 0.55 , respectively.

Dibajnia (1995) argued that concerning the rippled beds the value of $\omega_{\mathrm{cr}}$ should be smaller than 1 and proposed a variation of $\omega_{\mathrm{cr}}$ as a function of the skin Shields parameter $\theta_{s}$ :

$$
\begin{array}{ll}
\theta_{s} \leq 0.2 & \omega_{c r}=0.03 \\
0.2 \leq \theta_{s} \leq 0.6 & \omega_{c r}=1-0.97 \sqrt{1-\left(\left(\theta_{s}-0.2\right) / 0.4\right)^{2}} \\
0.6 \leq \theta_{s} & \omega_{c r}=1
\end{array}
$$

where,

$\theta_{s}=\frac{\tau_{b s}}{\rho\left(s^{-1}\right) g d_{50}}$

and $\tau_{\mathrm{bs}}$ represents the bed shear stress (skin friction contribution), also termed as effective stress (Nielsen, 1992). Eq. (7) should be understood as an indirect way to reproduce the dependence of the height $\Delta_{\mathrm{s}}$ on bed forms.

\subsection{Oblique wave-current flows}

Consider a wave propagating in the $O X$ direction with a near bed velocity $\vec{u}_{w}(t)$ in the presence of a steady current, $\vec{U}_{0}$, whose direction makes an angle of $\varphi$ with $O X$, as shown in Fig. 2.

Let $U_{o x}$ and $U_{o y}$ represent the steady current components in the wave direction and in the direction perpendicular to it, with unit vectors $\vec{i}$ and $\vec{j}$ :

$\vec{U}_{0}=U_{0} \cos (\varphi) \vec{i}+U_{0} \sin (\varphi) \vec{j}$ 
In the wave direction, the velocity time series, denoted by $u_{x}$ $(t)$, has a similar shape to the one depicted in Fig. 1. Like the collinear case, the time durations of the positive half cycle, $T_{c}$, and of the negative half cycle, $T_{t}$, are defined in this direction and the equivalent sinusoidal velocity amplitudes, $u_{c x}$ and $u_{t x}$ are given by:

$u_{c x}^{2}=\frac{2}{T_{c}} \int_{0}^{T_{c}} u_{x}^{2}(t) \mathrm{d} t \quad u_{t x}^{2}=\frac{2}{T_{t}} \int_{T_{c}}^{T} u_{x}^{2}(t) \mathrm{d} t$

In the $O Y$ direction, $u_{y}(t)=U_{0} \sin (\varphi)$, and the integration of Eq. (1) gives:

$u_{c y}^{2}=u_{t y}^{2}=2 U_{0}^{2} \sin ^{2}(\varphi)$

The equivalent sinusoidal velocity amplitudes in both positive and negative half cycles can be thought of as vector quantities:

$\vec{u}_{c}=u_{c x} \vec{i}+u_{c y} \vec{j} ; \vec{u}_{t}=-u_{t x} \vec{i}+u_{t y} \vec{j}$

with magnitudes $u_{c}$ and $u_{t}$ given by:

$u_{c}^{2}=\frac{2}{T_{c}} \int_{0}^{T_{c}}\|\vec{u}(t)\|^{2} \mathrm{~d} t=u_{c x}^{2}+2 U_{0}^{2} \sin ^{2}(\varphi)$

$u_{t}^{2}=\frac{2}{T_{t}} \int_{T_{c}}^{T}\|\vec{u}(t)\|^{2} \mathrm{~d} t=u_{t x}^{2}+2 U_{0}^{2} \sin ^{2}(\varphi)$

The net sediment transport rate during the wave period is given by:

$\frac{\overrightarrow{\mathrm{q}}_{s}}{w_{0} d_{50}}=\alpha \frac{\vec{\Gamma}}{|\Gamma|^{1-\beta}}$

with

$\vec{\Gamma}=\Gamma_{x} \vec{i}+\Gamma_{y} \vec{j}=\frac{\vec{u}_{c} T_{c}\left(\Omega_{c}^{3}+\Omega_{t}^{3}\right)+\vec{u}_{t} T_{t}\left(\Omega_{t}^{3}+\Omega_{c}^{3}\right)}{T\left(u_{c}+u_{t}\right)}$

and

$\Gamma_{x}=\frac{u_{c x} T_{c}\left(\Omega_{c}^{3}+\Omega_{t}^{3}\right)-u_{t x} T_{t}\left(\Omega_{t}^{3}+\Omega_{c}^{3}\right)}{T\left(u_{c}+u_{t}\right)}$

$\Gamma_{y}=\frac{\sqrt{2} U_{0} \sin (\varphi)\left(T_{c} \Psi_{c}^{3}+T_{t} \Psi_{t}^{3}\right)}{T\left(u_{c}+u_{t}\right)}$

In Eq. (18) we have considered that the sediment transport in the direction perpendicular to the wave is independent of the exchange of sediment between the two half cycles in the wave direction. It should be stressed that the mobility number, $\Psi_{i}$, in Eq. (6) is computed in terms of the magnitude of $\vec{u}_{c}$ and $\vec{u}_{t}$,
Eqs. (13) and (14). The equations of the model equate to the Eqs. (2) and (3), when $\varphi=0^{\circ}$.

\subsection{Steady currents}

The extension of the sediment transport model to the case of a steady current is established by analysing the model equations when the amplitude of the wave orbital velocity tends towards zero. Consider a sinus wave with orbital velocity amplitude $U_{w}$ and a steady current whose direction is (i) collinear or (ii) perpendicular to the wave direction. When $U_{w}$ is smaller than $U_{0}$ (assuming $U_{0}>0$ ), we obtain the following simplified equations for the case (i): $T_{c}=T ; T_{t}=0 ; u_{c}^{2}=U_{w}^{2}+2 U_{0}^{2} ; u_{t}=0$ and for the case (ii): $T_{c}=T_{t}=T / 2 ; u_{c x}^{2}=u_{t x}^{2}=U_{w}^{2} ; u_{c y}^{2}=u_{t y}^{2}=2 U_{0}^{2}$. As $U_{w}$ tends towards zero, while keeping $U_{0}$ constant, we obtain:

$$
\text { for case(i) } \quad \Gamma=\Psi_{c}^{3}=\left(\frac{2 U_{0}^{2}}{(s-1) g d_{50}}\right)^{3}
$$

for case(ii) $\quad \Gamma=\Psi_{c}^{3} / 2$

The disparity between the two solutions occurs because Eq. (16) has a discontinuity in this limiting situation. By replacing the denominator in this equation by $2\left(T_{c} u_{c}+T_{t} u_{t}\right)$, then gives:

$\vec{\Gamma}=\Gamma_{x} \vec{i}+\Gamma_{y} \vec{j}=\frac{\overrightarrow{\mathrm{u}}_{c} T_{c}\left(\Omega_{c}^{3}+\Omega_{t}^{3}\right)+\overrightarrow{\mathrm{u}}_{t} T_{t}\left(\Omega_{t}^{3}+\Omega_{c}^{3}\right)}{u_{c} T_{c}+u_{t} T_{t}}$

Therefore, in both cases, $\Gamma$ is given by Eq. (20). The factor 2 , omitted in the denominator of Eq. (21), is inserted in the value of constant $\alpha$ in Eq. (15). Eq. (21) will be considered below.

\section{Parameterization of the characteristic variables of the model}

In order to compute the sediment transport rate from the model Eqs. (15) and (21) it's necessary to know the values of $u_{c x}, u_{t x}, T_{c}$ and $T_{t}$ during the wave cycle. Note that the values of $u_{c y}$ and $u_{t y}$ are already given in Eq. (11). The values of $T_{c}$ and $T_{t}$ can be computed from the analysis of the velocity time series in the wave direction and $u_{c x}$ and $u_{t x}$ from the numerical integration of the Eq. (10).

For a regular wave field, in the presence of a steady current, the near bed velocity in the wave direction, $u_{x}(t)$ is a known function:

$u_{x}(t)=u_{w}(t)+U_{0 x}$

where $u_{w}(t)$ represents the wave orbital velocity. In this case, we can find exact analytical expressions for $u_{c x}, u_{t x}, T_{c}$ and $T_{t}$ as a function of the root mean square value of the orbital velocity, $u_{\mathrm{rms}}$ (or, equally, as a function of the wave orbital velocity amplitude, $U_{w}$ ), the wave "vertical asymmetry" (non-linearity), $r$, and in the ratio $r_{c}$ of the mean current flow 
in the wave direction, $U_{0 x}$, and $U_{w}$. These parameters are defined as:

$u_{\mathrm{rms}}^{2}=\frac{1}{T} \int_{0}^{T} u_{w}^{2}(t) \mathrm{d} t$

$r=\frac{U_{w \max }-\left|U_{w \min }\right|}{U_{w \max }+\left|U_{w \min }\right|}$

$r_{c}=U_{0 x} / U_{w}$

In Eq. (24), $U_{w \max }$ and $U_{w \min }$ represent, respectively, the maximum (positive) and minimum (negative) values of $u_{w}(t)$ during the wave period, with:

$2 U_{w}=U_{w \max }+\left|U_{w \min }\right|$

The functional form of these relations depends on the type of flow considered and in the formulation used to describe the wave. Herein we assume a flow condition composed of a regular wave (sinus wave, 2nd order Stokes wave or a sawtooth wave) in the presence (or not) of a steady current. The extension to cnoidal waves has been presented in Silva and Temperville (2000). In the case of an irregular wave field, the model calculates $T_{i}$ and $u_{i x}$ by analysing the velocity signal or by assuming that an equivalent regular wave can describe the train of irregular waves (in the sense that it gives the same sediment transport rate).

\subsection{2nd order Stokes wave and sinus wave}

The wave orbital velocity for a 2 nd order Stokes wave is given by:

$u_{w}(t)=u_{1} \cos (\omega t)+u_{2} \cos (2 \omega t)$

where $\omega$ represents the wave frequency. The former equation can be written as:

$u_{w}(t)=u_{1} f(t)$ with $f(t)=\cos (\omega t)+r \cos (2 \omega t)$

The root mean square value of the wave orbital velocity, Eq. (23), can be expressed as:

$u_{\mathrm{rms}}^{2}=\frac{u_{1}^{2}}{2}\left(1+r^{2}\right)$

Substitution of Eq. (22) into Eq. (10), with $u_{w}$ given by Eq. (28), gives the following after it has been integrated:

(i) for the positive half cycle:

$u_{c x}^{2}=u_{1}^{2} \gamma_{c}^{2}$

(ii) for the negative half cycle:

$u_{t x}^{2}=u_{1}^{2} \gamma_{t}^{2}$ with

$\gamma_{c}^{2}=1+r^{2}+2 r_{c}^{2}+\frac{\gamma_{p}}{\pi t_{c}}$

$\gamma_{t}^{2}=1+r^{2}+2 r_{c}^{2}-\frac{\gamma_{p}}{\pi\left(1-t_{c}\right)}$

The factor $\gamma_{p}$ in the last equations is given by:

$\gamma_{p}=\frac{1}{6} \sin \left(\pi t_{c}\right)\left[13 r+19 r_{c}+X\left(18 r r_{c}+1\right)\right]$

where, $t_{c}$ represents the dimensionless value of $T_{c}$,

$T_{c}=t_{c} T$

$T_{t}=\left(1-t_{c}\right) T$

and $X$ is given by:

$X=\cos \left(\pi t_{c}\right)=\frac{-1+\sqrt{1+8 r^{2}-8 r r_{c}}}{4 r}$

For the particular case of a sinus wave $(r=0)$ :

$X=\cos \left(\pi t_{c}\right)=-r_{c}$

The time duration of each half cycle can be found from solving either Eq. (37) or Eq. (38).

\subsection{Sawtooth wave}

Consider a skew wave in the form of a sawtooth wave as represented in Fig. 3. When $t \geq 0$, the velocity time series is written as:

$u_{w}(t)=U_{w} f(t)$

with

$f(t)=\left\{\begin{array}{cc}\frac{2 t}{s_{k} T} & t \leq \frac{s_{k} T}{2} \\ T-2 t & \frac{s_{k} T}{2} \leq t \leq \frac{T}{2}\end{array}\right.$

The factor $s_{k}$ denotes the wave "horizontal asymmetry", $s_{k}=$ $T_{p c} / T_{c}$, where $T_{p c}$ represents the instant where $u_{w}(t)$ attains the

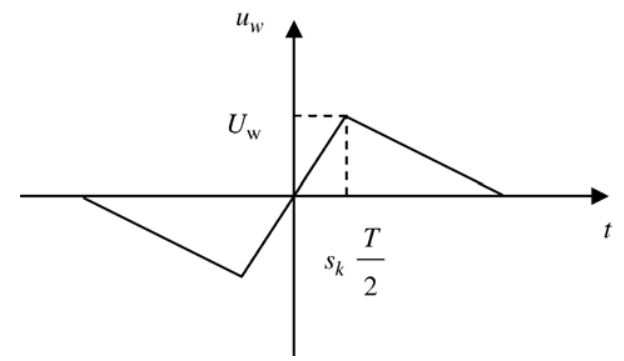

Fig. 3. Sawtooth wave velocity time series. 
maximum value (if $s_{k}=0.5$ the wave is symmetric). The root mean square value of the wave orbital velocity is given by:

$u_{\mathrm{rms}}^{2}=\frac{U_{w}^{2}}{3}$

As before, substitution of Eq. (22) into Eq. (10), with $u_{w}(t)$ given by Eqs. (39) and (40), equates Eqs. (30) and (31) (where $u_{1}$ is replaced by $U_{w}$ ) with:

$\gamma_{c}^{2}=\frac{2\left(1+r_{c}\right)^{2}}{3} ; \gamma_{t}^{2}=\frac{2\left(1-r_{c}\right)^{2}}{3}$

and,

$T_{c}=\frac{T}{2}\left(1+r_{c}\right) ; T_{t}=\frac{T}{2}\left(1-r_{c}\right)$ (43):

When $U_{0 x}=0$, we obtain the following from Eqs. (42) and

$u_{c x}^{2}=u_{t x}^{2}=\frac{2}{3} U_{w}^{2}$

$T_{c}=T_{c}=\frac{T}{2}$

According to Eq. (17), we get a zero net sediment transport, which is known to be generally unrealistic (Watanabe and Sato, 2004).

\section{Application of the $D \& W$ model to different flow conditions}

Herein we present a comparison of the net sediment transport rate computed with the model of D\&W with experimental measured values. By the D\&W model we mean the original formulation presented in 1992, modified by the denominator of $\vec{\Gamma}$ as established in Eq. (21). A large set of data considering different flow conditions (wave-current flows, purely oscillatory flow and steady currents), different regimes (plane bed and rippled bed) with uniform sand is considered in this study. We have restricted this analysis to collinear wave-current flows.

Table 1 presents an overview of the data set, specifying for each condition some of the experimental conditions considered and the reference made. The values of $\theta_{s}$ presented in Table 1 for the wave and wave-current combined flows, represent the maximum values of the skin Shields parameter over the wave cycle. These values are computed from Eq. (8) in terms of the peak bed shear stress, $\tau_{b \max }$, which is calculated from Soulsby et al. (1993):

$\frac{\tau_{b \max }}{\tau_{c}+\tau_{w}}=1+a X^{m}(1-X)^{n}$

with,

$X=\frac{\tau_{c}}{\tau_{c}+\tau_{w}}$

The quantities $a, m$ and $n$ in Eq. (46) are constants. The wave bed shear stress, $\tau_{w}$, is computed from:

$\tau_{w}=\frac{1}{2} \rho f_{w} U_{w}^{2}$

The wave friction factor, $f_{w}$, is computed with the Swart formula (Swart, 1974):

$f_{w}=0.00251 \exp \left[5.21\left(\frac{a_{w}}{K_{s}}\right)^{-0.19}\right] \quad a_{w} / K_{s}>1.57$

$f_{w}=0.3 \quad a_{w} / K_{s} \leq 1.57$

The wave semi-orbital excursion, $a_{w}$, is given by:

$a_{w}=\frac{U_{w} T}{2 \pi}$

The current bed shear stress, $\tau_{\mathrm{c}}$, is computed from:

$\tau_{b}=\frac{1}{2} \rho f_{c} U_{0}^{2}$

and the current friction factor, $f_{c}$, is computed assuming a logarithmic vertical velocity profile:

$f_{c}=2\left[\frac{0.4}{\ln \left(h / z_{0}\right)-1}\right]^{2}$

In the case of a steady current the values of $\theta_{s}$ were computed from Eq. (8) using Eqs. (51) and (52).

Table 1

Overview of the data set considered in the applications of the model

\begin{tabular}{|c|c|c|c|c|c|c|}
\hline & Flow condition & Regime & Range of $\theta_{s}$ & $d_{50}(\mathrm{~mm})$ & $n^{\circ}$ tests & Reference \\
\hline Series B & stk & $s f+r$ & $0.14-2.08$ & 0.21 & 20 & Ribberink and Al-Salem (1994) \\
\hline Series C & $s t k+c$ & $s f$ & $0.84-1.96$ & 0.21 & 10 & Koelewijn and Ribberink (1994) \\
\hline Series E $+\mathrm{J}$ & $w \sin +c$ & $s f$ & $0.57-3.26$ & 0.21 & 10 & Katopodi et al. (1994); Dohmen-Janssen (1999) \\
\hline Series H & $w \sin +c$ & $s f$ & $0.90-3.92$ & 0.13 & 12 & Dohmen-Janssen (1999) \\
\hline Series I & $w \sin +c$ & $s f$ & $0.64-2.47$ & 0.32 & 5 & Dohmen-Janssen (1999) \\
\hline Series R & stk & $s f$ & $0.7-1.38$ & 0.34 & 5 & Hassan (2003) \\
\hline WI & $s t k+c$ & $r$ & $0.08-0.63$ & $0.18 ; 0.87$ & 54 & Watanabe and Isobe (1990) \\
\hline SY & $w \sin$ & plane bed & - & $0.2 ; 0.7 ; 1.8$ & 15 & Sawamoto and Yamashita (1986) \\
\hline ND & $c$ & $s f$ & $0.80-7.7$ & 0.7 & 47 & Nnadi and Wilson (1992) \\
\hline VOG1 & $c$ & $d n$ & $0.5-1.76$ & $0.18-0.25$ & 60 & Voogt et al. (1991) \\
\hline VOG2 & $c$ & $d n$ & $0.4-1.6$ & $0.23-0.35$ & 60 & Voogt et al. (1991) \\
\hline
\end{tabular}

Note. $s f$ - sheet flow; $r$ - rippled bed; $d n$ - dunes; wsin — sinus wave; stk - 2nd order Stokes wave; $c$ - steady current. 

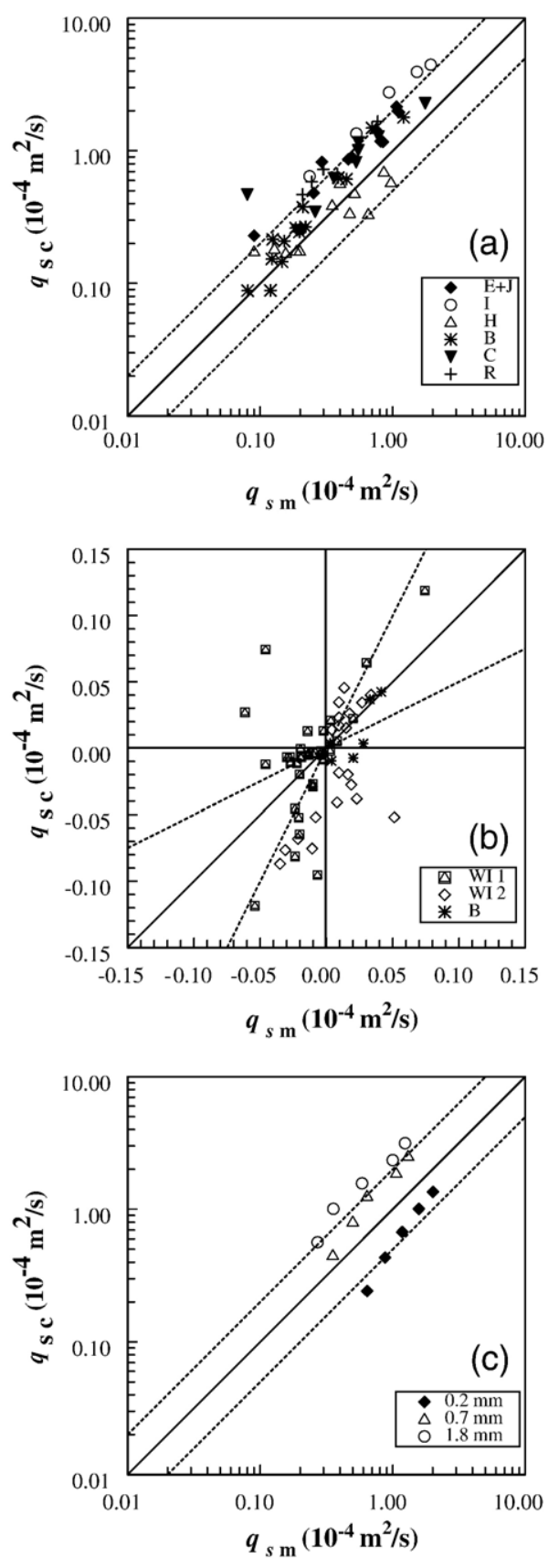

Fig. 4. Measured against predicted net transport rates with D\&W model for (a) SF1; (b) RP1 and (c) SY data set.

In any test condition, the Nikuradse equivalent grain roughness height, $K_{s}$, was set equal to $2.5 d_{50}$ and the roughness length, $z_{0}$, in Eq. (52) is computed from $K_{s}, z_{0}=K_{s} / 30$. The sediment fall velocity is computed according to Soulsby's (1997) formula.

\subsection{Wave and combined wave-current flows}

The wave and combined wave-current experiments described in Table 1 were performed in oscillating water tunnels (OWT): series B, C, E, H, I, J and R at the LOWT of WL |Delft
Hydraulics and the WI and SY experiments at the University of Tokyo OWT. The net transport rate during the wave cycle was measured for all test conditions except for SY tests. In this experiment, five test conditions were performed with identical hydraulic conditions (purely sinusoidal oscillatory motion) for three different grain sizes: $d_{50}=0.2,0.7$ and $1.8 \mathrm{~mm}$. The sediment transport over half the wave cycle was measured for each condition.

Fig. 4 compares the computed, $q_{s c}$, and measured, $q_{s m}$, values of the net sediment transport rate during the wave cycle for different test conditions in sheet flow and rippled beds. The ensemble of tests conditions in the sheet flow regime, corresponding to the series $B, C, E, H, I, J$ and $R$ is denoted by the SF1 data set, while the ensemble of tests with rippled bed corresponding to Series B and WI are denoted by the RP1 data set. For the WI experiments we have distinguished in Fig. 4b between the $d_{50}=0.18 \mathrm{~mm}$ sediment (denoted by WI1) and the coarse sediment with $d_{50}=0.87$ (denoted by WI2). Fig. 4c represents the solutions obtained for the SY data. The dash lines in these figures represent the factor of 2 and the solid line represents perfect agreement between the predicted and measured net transport rates.

In the case of sheet flow conditions, the percentage of the computed values of $q_{s}$ within a factor of 2 is $75 \%$. Fig. 4 a shows some dependency of the computed values on the sediment grain size. For the coarser sediments (series I and $\mathrm{R}, d_{50}=0.32$ and $0.34 \mathrm{~mm}$, respectively) the model overpredicts the experimental values, while for the more fine sediments (series $\mathrm{H}, d_{50}=0.13 \mathrm{~mm}$ ), some under prediction occurs. Therefore, the performance of the formula depends on the sediment grain size, a feature that is also apparent in Fig. 4c for the SY experiments.

The analysis of the numerical results in the sheet flow regime reveals that the phase lag effects predicted by the model are only effective for the test conditions with $\theta_{s}>2.3$, e.g. in series $\mathrm{H}$, experimental conditions H4, H5, H6 and H44. Fig. 5 illustrates the computed and measured values of the net sediment transport as a function of $\theta_{s}$, for the H2-H6 conditions. The values of $T$ and $U_{0}$ were kept constant while the orbital velocity amplitude increases from $\mathrm{H} 2$ to H6. It is seen that the model tends to underestimate the experimental values of $q_{s}$ for increasing values of $\theta_{s}$. This disparity is due to the fact that the D\&W model predicts an exchange of sediments from the positive to the negative half cycle while experiments apparently do not yet show these effects.

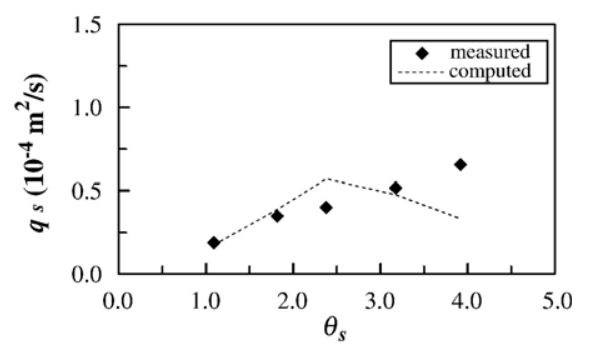

Fig. 5. Comparison between the measured (symbols) and computed (dash line) values of $q_{s}$ for the $\mathrm{H} 2-\mathrm{H} 6$ conditions in series $\mathrm{H}$. 

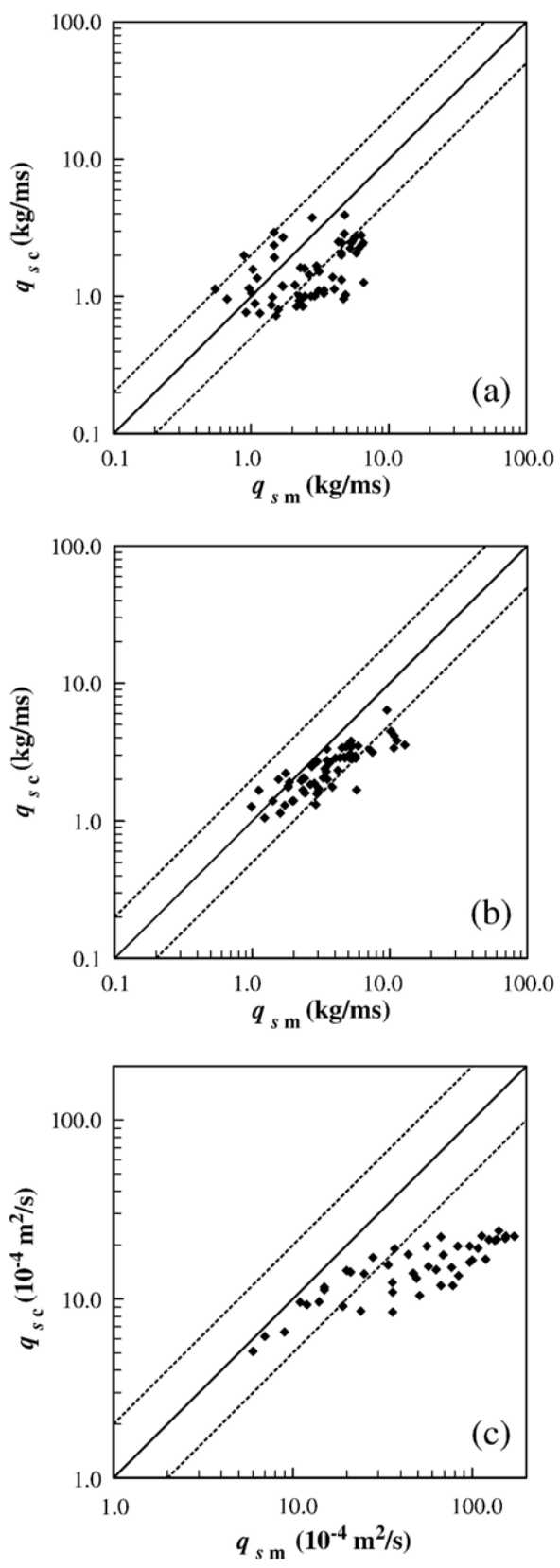

Fig. 6. Measured against predicted net transport rates with D\&W model for (a) VOG1, (b) VOG2 and (c) ND data sets.

The results obtained for rippled bed conditions (Fig. 4b), show more scatter than for sheet flow conditions: in $20 \%$ of the tests the model does not reproduce the direction of the transport and the percentage of the computed values of $q_{s}$ within a factor of 2 is $27 \%$. We can name two different reasons for this discrepancy. One is that the structure of the flow over rippled beds is complex. The vortex structures formed in the lee side of the ripples capture and retain large amounts of sediment entrained from the bottom which gives rise to a strong exchange of sediments between the two half cycles. These well-known complex vortices processes are not properly modelled in the $\mathrm{D} \& \mathrm{~W}$ model. On the other hand, the measured values of $q_{s}$ are one or more orders of magnitude lower than the values obtained in sheet flow conditions. Therefore, the importance of experimental errors in the total transport rate can be significant.

\subsection{Steady flows}

The VOG 1, 2 data were obtained from surveys in two tidal channels in the Eastern and Western Scheldt estuary, The Netherlands (Voogt et al., 1991). Echo-sounding profiles of the bed revealed the presence of bed forms, symmetric and anti-symmetric sand dunes, whose dimensions are a function of the tidal peak velocity (heights between 3.5 and $6 \mathrm{~m}$ and wavelengths between 10 and $30 \mathrm{~m}$ ). Fig. $6 \mathrm{a}, \mathrm{b}$ compare the computed values of $q_{s}$ with the measured ones. The model underestimates the measured values: the percentage of computed values within a factor of 2 is $53 \%$ for VOG1 and $83 \%$ for VOG2 data.

The experiments reported by Nnadi and Wilson (1992) ND -, were performed in a pressurised closed conduit with a small cross section $(10 \times 10 \mathrm{~cm})$. Plane bed conditions were observed for all the tests. Fig. 6c illustrates the model's performance in this case. It is seen that the ratio $q_{s c} / q_{s m}$ is smaller than one for all tests and decreases as the bed shear stress increases ( $U_{0}$ increases).

\section{New semi-unsteady model: formulation and model verification}

The application of the D\&W model to the large data set presented above has shown that the model has some shortcomings, namely:

(i) the effect of sediment size is apparently not properly taken into account in the formula;

(ii) the computed sediment transport rates do not correlate well with the measurements when non-steady conditions prevail, both in sheet flow conditions and rippled bed conditions;

(iii) for a steady current the agreement with experimental results is poor, especially for the high flow regime.

In this section we start by analysing the two first issues pointed out above and in Section 5.3 we propose an improved version of the model that is applicable to more general flow conditions relevant in the near shore coastal zone.

\subsection{Grain size dependence}

Systematic disparities due to the effects of sediment size have already been recognized by Dibajnia and Watanabe (1996). These authors have proposed a modification of the formula that computes $\Omega_{i}$ for each half cycle, Eq. (5), assuming that the sediment transport rate is proportional to the third power of the ratio between the equivalent velocity and the sediment fall velocity. The calibration and verification of this model was accomplished using the SY and WI data, referenced above. The applications performed by Silva (2001) with the 1996 version of D\&W model, have shown, however, that the 
model's performance is still dependent on the sediment grain size.

The performance of the model can be improved if we consider the normalized parameter of $q_{s}$ as in Ribberink (1998) and others:

$\frac{\vec{q}_{s}}{\sqrt{\left(s^{-1}\right) g d_{50}^{3}}}=\alpha|\Gamma|^{\beta} \frac{\vec{\Gamma}}{|\Gamma|}$

This corresponds to $w_{0}=\sqrt{\left(s^{-1}\right) g d_{50}}$ in Eq. (15). The computed values of sediment transport rate according to Eq. (53) are compared with measured values in Fig. 7a, b and
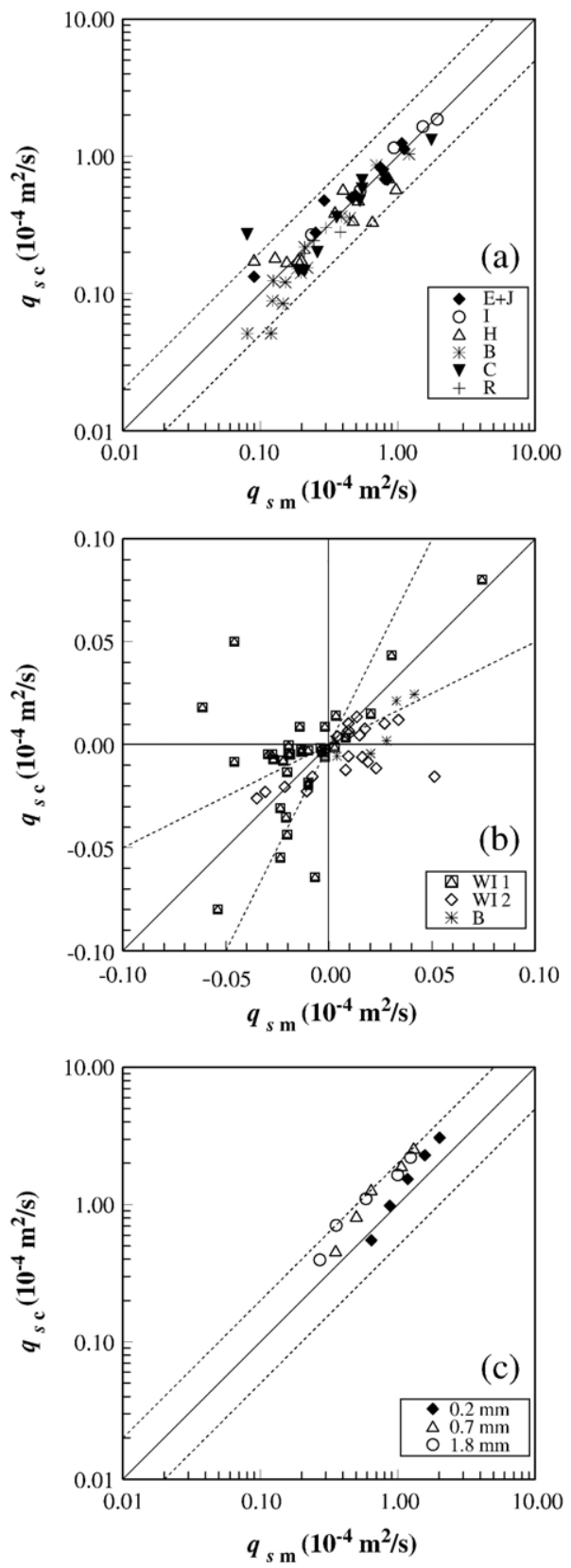

Fig. 7. Measured against predicted transport rates with the model based on Eq. (53) for (a) SF1, (b) RP1 and (c) SY data.
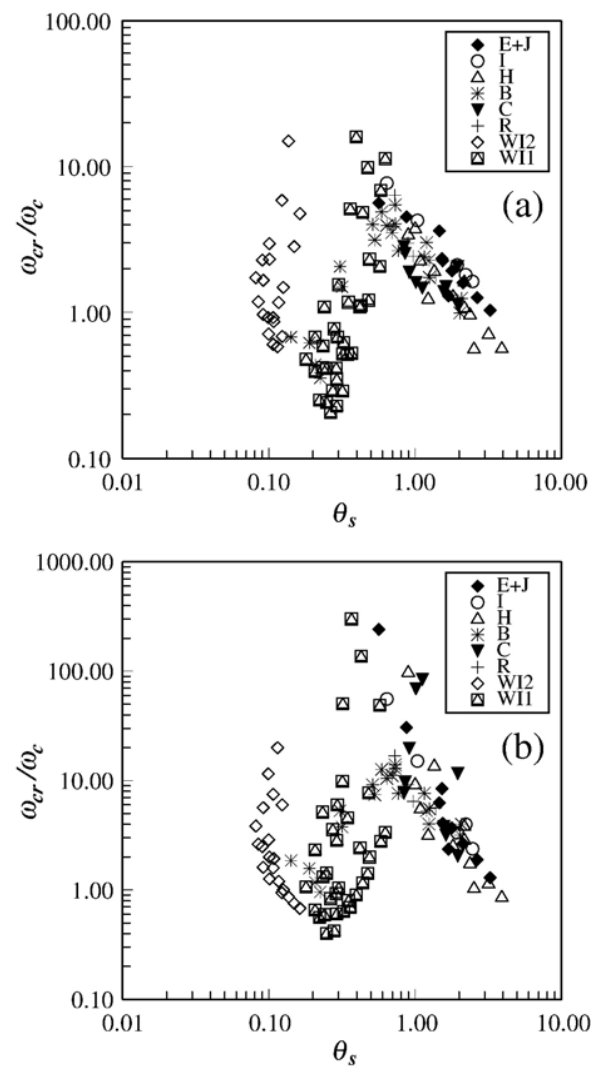

Fig. 8. The ratios (a) $\omega_{c r} / \omega_{c}$ and (b) $\omega_{c r} / \omega_{t}$ as a function of $\theta_{s}$, for SF1 and RP1 data.

c. The values of the coefficients $\alpha$ and $\beta$ in Eq. (53) have been found by performing a linear regression analysis: $\alpha=0.00019$ and $\beta=0.55$. It is observed that the model's performance no longer depends in the sediment grain size: compare, for example, the results obtained for series I $\left(d_{50}=0.32 \mathrm{~mm}\right)$ and $\mathrm{H}$ $\left(d_{50}=0.13 \mathrm{~mm}\right)$ in Figs. $4 \mathrm{a}$ and $7 \mathrm{a}$. The same improvements are noticeable for the RP1 and SY data, illustrated in Fig. 7b and c, respectively.

\subsection{Adjustment of $\omega_{c r}$}

Fig. 8 represents the ratio of the values of $\omega_{c r}$ computed from Eq. (7) and the values of the phase lag parameter for each half cycle, $\omega_{i}$, as a function of the skin Shields parameter, $\theta_{s}$, for the SF1 and RP1 data.

As stated before, for values of the ratio $\omega_{c r} / \omega_{i}$ lower than 1 , the exchange of sediments between the two half cycles occurs, meaning that phase lag effects between the velocities and sediment concentration becomes important. Fig. 8 shows that for $\theta_{s} \approx 0.6$ large values of $\omega_{c r} / \omega_{i}$ are found. For increasing $\theta_{s}$ (sheet flow regime) the ratio $\omega_{c r} / \omega_{i}$ decreases, but becomes smaller than 1 only for $\theta_{s}>2.3$. This occurs for some conditions of series H for which Dohmen-Janssen (1999) observed phase lag effects. For the rippled bed tests, the exchange mechanism is effective even for the conditions where $0.1<\theta_{s}<0.5$. It became evident when analysing Fig. $7 a$ and $b$ that there is a large scatter of the plotted points for these two data set conditions. Therefore, 
we may conclude that the $\mathrm{D} \& \mathrm{~W}$ model seems to predict the situations when the phase lag effects occur, but it does not correctly reproduce the enhancement or reduction of sediment transport rate in the wave direction due to this mechanism.

The main uncertainty in the computation of the model parameter $\omega_{i}$, which controls phase lag effects (see Eq. (4)), is the height to which the sediments are entrained into the flow, $\Delta_{\mathrm{s}}$. In sheet flow conditions, this height is closely related to the thickness of the sand sheet flow layer, $\delta_{\mathrm{sf}}$, because almost all sediment is contained there. It is recognized from several studies, that $\delta_{\mathrm{sf}}$ is proportional to the skin Shields parameter (Wilson, 1989; Dohmen-Janssen, 1999) and also to the semi-excursion (Ahmed and Sato, 2003). This height can be limited by turbulent kinetic energy dissipation due to the high sediment concentrations in the sheet flow layer (which induces a reduction of the eddy viscosity). The numerical simulations of the oscillatory bottom boundary layer performed by Tran Thu (1995) with a 1DV model, have shown that turbulent kinetic energy dissipation due to sediment stratification should be considered in order to properly reproduce the vertical distributions of the mean sediment concentration over the wave cycle. Based on observational results, Ribberink and AlSalem (1994) have suggested that turbulent kinetic energy dissipation affects the thickness of the sheet flow layer and that this dissipation increases with $\theta_{s}$. These arguments are not compatible with the D\&W hypothesis (see the derivation of the right hand side of Eq. (4) and Eq. (7), where the value of $\omega_{c r}$ is kept constant and equal to one in the sheet flow regime).

In the ripple regime, the values of $\Delta_{\mathrm{s}}$ are considerably larger than $\delta_{\text {sf }}$ due to the ejection of vortices around flow reversal. In this case, it is reasonable to think that the maximum height to which sediments are carried into the flow is related to the strength of the vortices and to the sand ripple dimensions. The authors do not know of an empirical law at present from which this distance could be calculated and it should be stressed that the prediction of ripples dimensions is commonly made by using empirical formulas obtained for particular data sets (see, for example, Nielsen, 1992).

On the other hand, it is also well-known that hindered settling is an effective mechanism in reducing the sediment fall velocity. Guizien et al. (2001) and Silva (2001) have found that for the series $\mathrm{H}$, the sediment fall velocity should be greatly reduced in the sheet flow layer in order to numerically reproduce (with a 1DV bottom boundary layer model) the mean values of sediment concentration in the sheet flow layer. Therefore, the maintenance of a constant value for $w_{s}$ in Eq. (4), calculated in terms of the bed material, does not seem to be acceptable, especially for sheet flow conditions, where the hindered settling effects are more effective.

Due to the complexity of the previously mentioned processes that may affect, on the one hand, the distance to which sediment is entrained into the flow, both in sheet flow and rippled bed regimes, and, on the other hand, the sediment settling velocity, added to the difficulty of parameterizing them as a function of the well-known characteristic flow parameters, we did not attempt to describe explicitly these processes in Eq. (4). Alternatively, we propose to describe implicitly their influence through an adjustment of the parameter $\omega_{c r}$ for which the numerical results are optimal. This was done in the following way as outlined below.
The parameter $\Gamma$ in Eq. (2) can be viewed as a product of two functions:

$\Gamma=G \Gamma_{N}$

$\Gamma_{N}$ represents the value of $\Gamma$ when the phase lag effects are not considered in the model (quasi-steady approach) and $G$ represents a function that translates the effect of the unsteady processes in sediment transport. An expression for $\Gamma_{N}$ can be derived from Eq. (3) (with the denominator changed as in Eq. (21)), assuming that the primed quantities, $\Omega_{i}^{\prime}$, are zero:

$\Gamma_{N}=\Psi_{c}^{3} \frac{1-\alpha_{o}^{7} \delta_{o}}{1+\alpha_{o} \delta_{o}}$

The function $G$ is given by:

$G=\frac{Z_{c}^{3}+\alpha_{o}^{6}\left(1-\beta_{o} Z_{c}\right)^{3}-\alpha_{0} \delta_{o}\left\lfloor\alpha_{o}^{6}\left(\beta_{o} Z_{c}\right)^{3}+\left(1-Z_{c}\right)^{3}\right\rfloor}{1-\alpha_{o}^{7} \delta_{o}}$

The quantities $\alpha_{o}, \delta_{o}, Z_{c}$ and $\beta_{o}$ in Eqs. (55) and (56) are given by:

$\alpha_{o}=\frac{u_{t}}{u_{c}} ; \delta_{o}=\frac{1-t_{c}}{t_{c}} ; Z_{c}=\frac{\omega_{c r}}{\omega_{c}} ; \beta_{o}=\frac{\omega_{c}}{\omega_{t}}$

In Eq. (56), when $\omega_{c r}>\omega_{c}$ and/or $\omega_{c r}>\omega_{t}$ (the exchange mechanism is not effective) the values of $Z_{c}$ and/or $\beta_{o} Z_{c}$ are set equal to one.

Using Eqs. (53), (54) and (55), the values of $G$ that verify the measured values of $q_{s}$ were computed. The "ideal" values of $\omega_{c r}$ that minimize the difference between the computed and the measured sand transport rates were then found by solving iteratively Eq. (56). Using this procedure, it was found (Silva, 2001) that the optimal values of $\omega_{c r}$ are a function of the skin Shields parameter. In the sheet flow regime $\left(\theta_{s}>0.6\right)$ :

$\omega_{c r}=a_{1}+b_{1} \theta_{s}+b_{2} \theta_{s}^{2}+b_{3} \theta_{s}^{3}$

with $a_{1}=-0.408, b_{1}=1.367, b_{2}=-0.511$ and $b_{3}=0.069$. In the ripple regime, for $0.2<\theta_{s}<0.6$, a dependence of the optimal values of $\omega_{c r}$ with $\theta_{s}$ was noticed. The proposed expression for $\omega_{c r}$ is analogous to Eq. (58) with $a_{1}=-0.053, b_{1}=0.39, b_{2}=0.28$ and $b_{3}=-0.161$. For the ensemble of tests corresponding to conditions $\theta_{s}<0.2$, the range of variation of the optimal values for $\omega_{c r}$ is between 0.02 and 0.05 , and do not show a clear relation with $\theta_{s}$. Therefore, a constant value of $\omega_{c r}$ was considered:

$\omega_{c r}=0.035 \quad\left(\theta_{s}<0.2\right)$

Fig. 9 represents the variation of $\omega_{c r}$ with $\theta_{s}$ according to Eq. (7) and the new proposed expression. It should be noted that this analysis confirms the general features of the dependence of $\omega_{c r}$ with $\theta_{s}$ as proposed by Dibajnia and Watanabe (1992) and Dibajnia (1995).

The comparison between the computed and measured values of the transport rates for the model based on Eqs. (53), (58) and (59) is illustrated in Fig. 10 for the SF1 and RP1 data. 


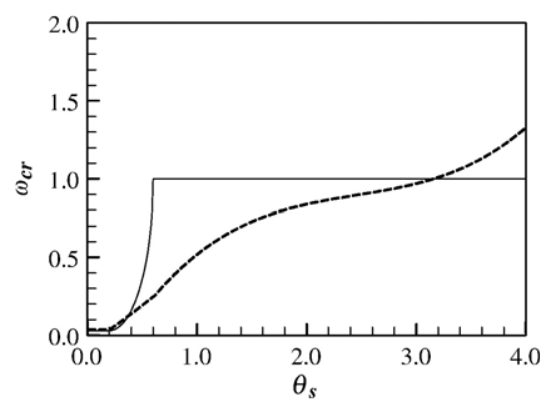

Fig. 9. Variation of $\omega_{c r}$ with $\theta_{s}$ according to Eqs. (7) - solid line, (58) and (59) - dash line.

Fig. 11 is analogous to Fig. 5 and shows that the proposed variation of $\omega_{c r}$ with $\theta_{s}$ in the sheet flow regime yields to a better agreement with the experimental results.

The comparison made between Fig. 10a and b with Fig. 4a and $\mathrm{b}$ shows that the modified D\&W model based on Eqs. (53), (58) and (59) gives a better description of the experimental results, both in the sheet flow and in the rippled bed regimes. In sheet flow conditions more than $95 \%$ of the computed values are within a factor of 2 while in rippled bed conditions this value is nearly $50 \%$. However, the model does not seem to substantially improve the performance in the rippled bed test cases where the direction of the transport has not already been well predicted (circa 20\%).
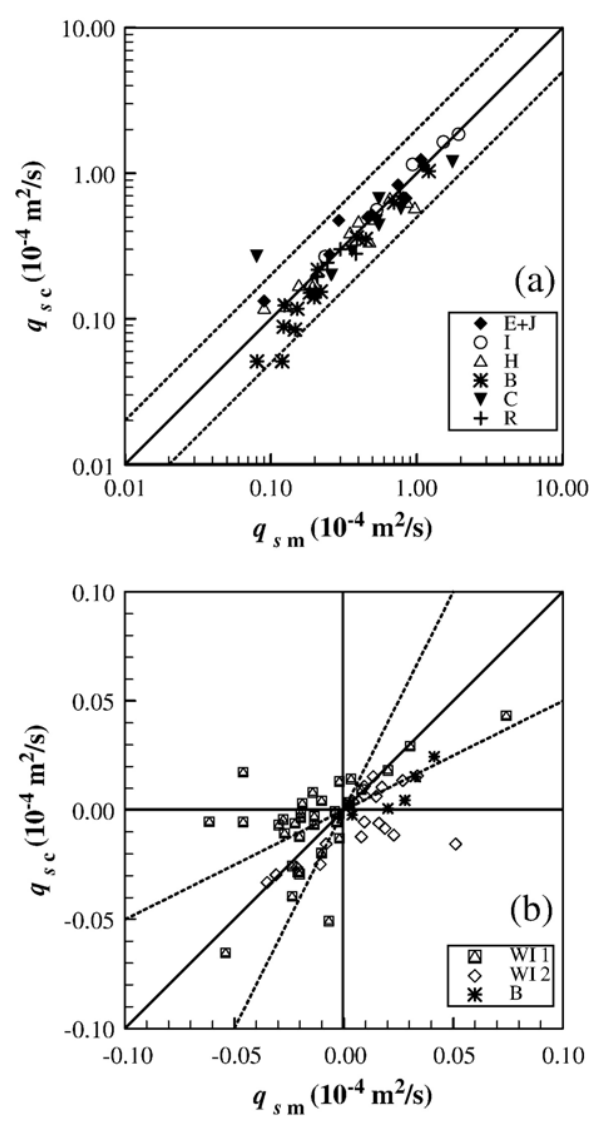

Fig. 10. Measured against predicted net transport rates for the model based on Eqs. (53), (58) and (59) for (a) SF1 and (b) RP1 data.

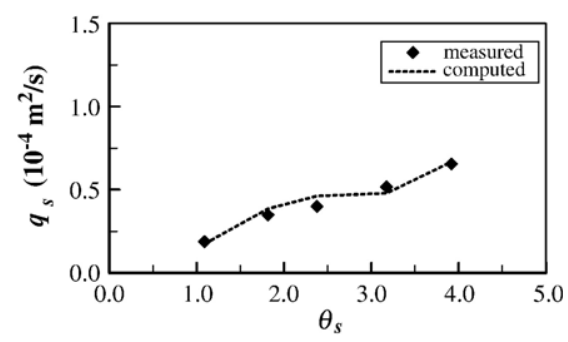

Fig. 11. Comparison between the measured (symbols) and computed (dash line) values of $q_{s}$ based on Eqs. (53), (58) and (59) for the H2-H6 conditions in series $\mathrm{H}$.

\subsection{New semi-unsteady model}

The agreement between the computed and the experimental values of the net sediment transport rate in wave and combined wave-current flows (see Fig. 10) suggests that for these kind of flows $q_{s}$ can be adequately computed in terms of the equivalent velocity amplitudes, $u_{c}$ and $u_{t}$; that is, in terms of the instantaneous velocity above the wave boundary layer. However, all the test conditions considered regular linear or non-linear waves. In a general way, waves are random and as they move and shoal towards a beach, apart from becoming asymmetrical due to the non-linearity, they also become skewed with steep front faces and more gently sloping rear faces. The corresponding orbital velocity field near the bottom also shows a similar profile, as illustrated schematically in Fig. 3 for a sawtooth wave.

During the time period corresponding to the steep front face of the wave, when the velocity flow varies rapidly from the maximum negative (offshore) value to the maximum positive (onshore) value, strong fluid accelerations are induced, while during the time corresponding to the rear face the accelerations induced by the flow are obviously not so large, i.e., $\frac{\overline{\mathrm{d} u^{3}}}{\mathrm{~d} t}>0$. This asymmetry of fluid accelerations in skewed waves is responsible, as shown by King (1991), Elgar et al. (2001) and Watanabe and Sato (2004), for a net shoreward sediment transport. The application of the preceding model formulated in terms of the equivalent mobility number to the velocity time series depicted in Fig. 3, however, gives a zero net sediment transport rate because of the symmetry of the two half cycles (see Section 3.2).

A possible way to describe the asymmetry of the fluid accelerations in the model is to calculate the sediment transport in terms of the bottom shear stress, or equivalently, in terms of the Shields parameter. Guizien and Temperville (1999) have computed the bottom shear stress with a 1DV bottom boundary layer model for a wave like the one depicted in Fig. 3 and have shown that the higher shear stress values (in absolute value) are obtained under the rapidly accelerated half cycle (see also Nielsen, 1992). The inclusion of the bed shear stress in the model should also improve the results for steady flow test conditions. In fact, according to Eq. (19), $q_{s}$ is a function of the depth average velocity. Therefore, the values of $q_{s}$ are identical for test conditions with the same $U_{0}$, independently of the flow depth.

The need to generalize the proposed model to suit the more general flows relevant in the coastal zones, has lead us to develop a new improved version of the model. This was accomplished by 
replacing the equivalent mobility number by an equivalent Shields parameter, $\theta_{i}$, defined for each half cycle, as:

$\theta_{i}=\frac{1}{2} \frac{f_{c w i} u_{i}^{2}}{(s-1) g d_{50}}$

and rewrite Eq. (5) as:

$$
\begin{aligned}
& \Omega_{i}=\left(\theta_{i}-\theta_{c r}\right) \min \left(1, \frac{\omega_{c r}}{\omega_{i}}\right) \\
& \Omega_{i}^{\prime}=\left(\theta_{i}-\theta_{c r}\right) \max \left(0,1-\frac{\omega_{c r}}{\omega_{i}}\right)
\end{aligned}
$$

In this formulation we have considered the critical value of the skin Shields parameter, $\theta_{c r}$, above which sediment movement starts. In Eq. (60) $f_{c w i}$ represents the wave-current friction factor for each half cycle $i$, which are computed accordingly to:

$f_{c w i}=\varepsilon f_{c}+(1-\varepsilon) f_{w i}$

with $\varepsilon=U_{0} /\left(U_{w}^{*}+U_{0}\right)$. In the positive half cycle $U_{w}^{*}=U_{w \max }$ while in the negative half cycle $U_{w}^{*}=\left|U_{w \min }\right|$. The values of $f_{w i}$ and $f_{\mathrm{c}}$ are computed from Eqs. (49a), (49b) and (52). The semiorbital excursion of the wave during each half cycle is computed as in Eq. (50), but assuming a wave with velocity amplitude $U_{w}^{*}$ and period $T$ equal to 4 times the time of peak velocities, $T_{p c}$ and $T_{p t}$ (see Fig. 1). As remarked by Dibajnia and Watanabe (1998), the exchange of sediments between the two half cycles can also depend on the degree of asymmetry, i.e., on the values of $T_{p c}$ and $T_{p t}$, because it changes the time available for sediment settling. In order to describe this process in the model we have assumed that $T_{i}$ in the Eq. (4) should be replaced by $2\left(T_{i}-T_{p i}\right)$ (see Silva, 2001 and Watanabe and Sato, 2004).

Calculation of the friction factors (bed shear stress) in Eqs. (60) and (62) also involves knowledge of the bed roughness, $K_{s}$. For sediment transport computations the bed shear stress exerted at the bottom should contain not only the skin friction contribution, that acts directly on the sediment grain particles, but also a form drag associated with the bed forms and a sediment transport contribution (Soulsby, 1997). The form drag results from differences in pressures around the bed forms and does not affect directly the stability of individual grain sediments. Sediment transport contribution arises from the momentum transfer between the flow and the moving grains at very high flow speeds (intense sheet flow). In this way, not only is the bed load transport accounted for in the model but the suspended load also is, as the intensity of turbulence near the bed, and hence the amount of sediment in suspension, is determined by the total shear stress.

Therefore, the bed roughness specified in Eqs. (49a), (49b) and (52) corresponds to a total roughness that includes contributions from the grain related, $K_{s s}$, form drag, $K_{s f}$ and sediment transport components, $K_{s t}$ :

$K_{s}=K_{s s}+K_{s f}+K_{s t}$

The grain related component is calculated in terms of the median grain sediment size, $K_{s s}=2.5 d_{50}$. The sediment tran-
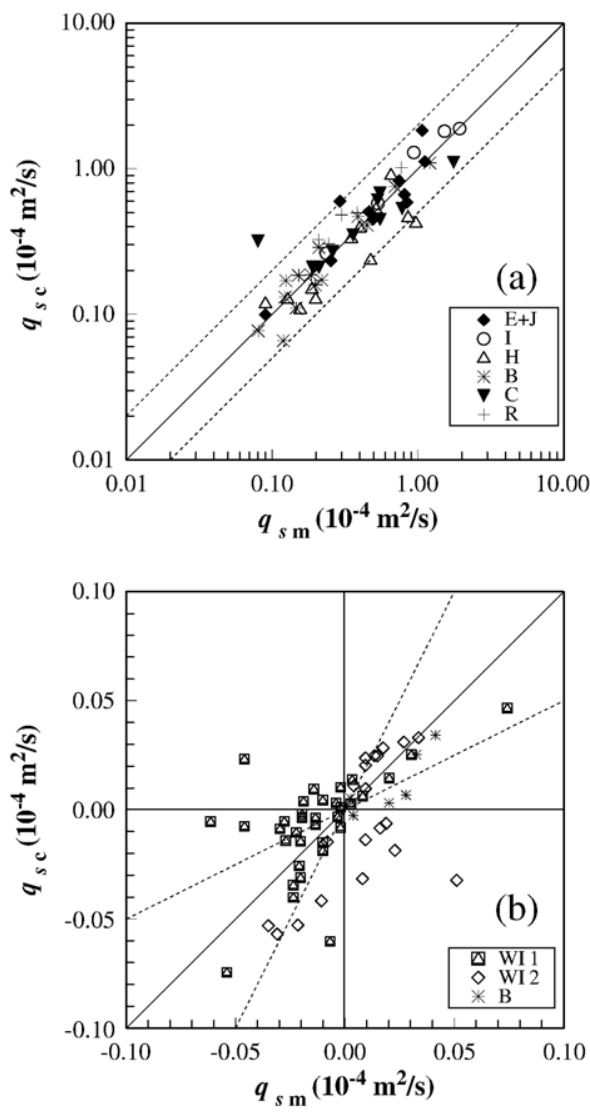

Fig. 12. Measured against predicted net transport rates for the model formulated in terms of the equivalent Shields parameter for (a) SF1 and (b) RP1 data.

sport component of roughness is related with the intensity of transport and is computed in terms of the skin Shields parameter (Wilson, 1989; Nielsen, 1992; Ribberink, 1998). We will consider the Wilson (1989) formula below:

$K_{s t}=5 \theta_{s} d_{50}$

The form drag component of the total roughness is commonly related to the height and steepness of the bed forms. For ripples in steady and oscillatory flows Nielsen (1992) proposed the following formula:

$K_{s f}=k h_{r}^{2} / \lambda_{r}$

where $k$ is a constant and $h_{\mathrm{r}}$ and $\lambda_{\mathrm{r}}$ represent, respectively, the height and length of the ripple. For steady currents, van Rijn (1984) has proposed a classification diagram for determining the type of bed forms in the lower and transitional regimes in terms of a transport stage parameter, $T$. This parameter is expressed in terms of the skin Shields parameter and the critical value $\theta_{c r}$. For dune type bed forms, the following formula for the form roughness was derived based on a large field and flume data set:

$K_{s f}=1.1 h_{d}\left(1-\exp \left(-25 h_{d} / \lambda_{d}\right)\right)$ 

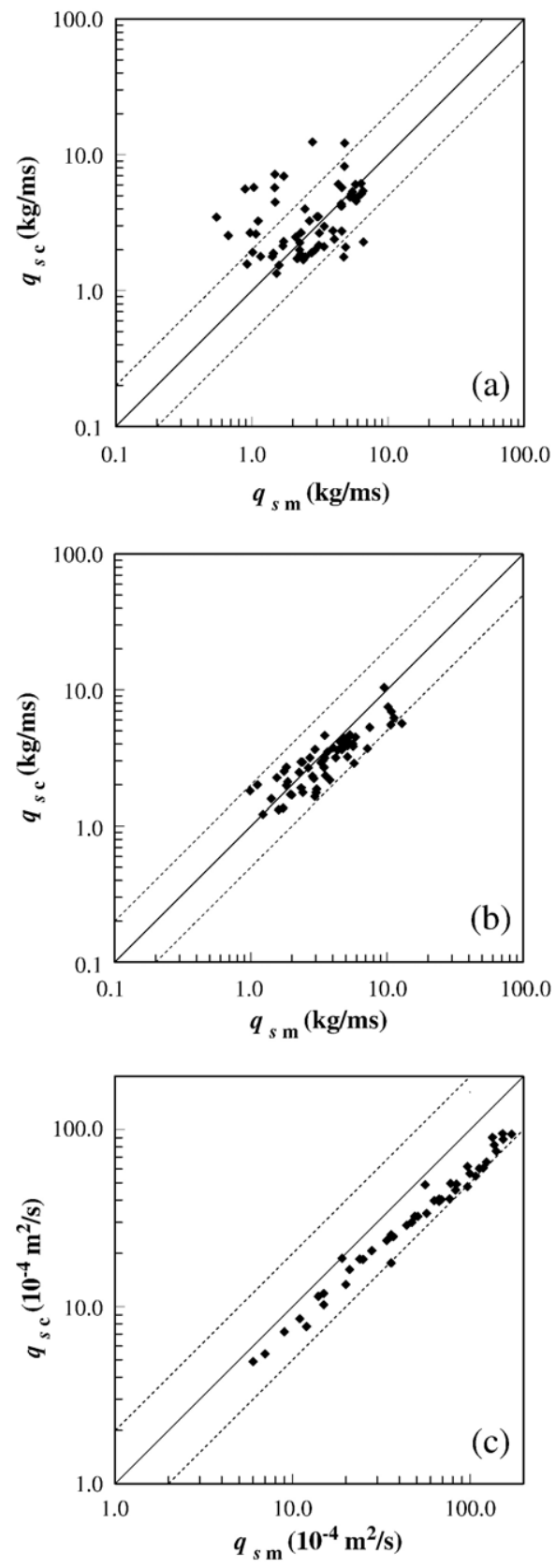

Fig. 13. Measured against predicted net transport rates for the model formulated in terms of the equivalent Shields parameter for (a) VOG1, (b) VOG2 and (c) ND data sets.

The dune height is related to the transport parameter, $T$, the flow depth, $h$, and the particle diameter, $d_{50}$, according to:

$h_{d}=0.11 h\left(d_{50} / h\right)^{0.3}(1-\exp (-0.5 T))(25-T)$

The bed form length depends only on the flow depth:

$\lambda_{d}=7.3 h$

The application of the model formulated in terms of the equivalent Shields parameter, Eq. (61), and considering Eqs. (53),
(58) and (59) to the SF1, RP1 and the steady current data sets is illustrated in Figs. 12 and 13. The values of the coefficients $\alpha$ and $\beta$ in Eq. (53) are equal to 3.2 and 0.55 , respectively.

The results obtained for the wave and combined wave current tests in sheet flow (SF1) and with rippled bed (RP1) data are equivalent to the ones already obtained with the model formulated in terms of the equivalent mobility number (see Fig. 10): the computed values within a factor of 2 are $95 \%$ for SF 1 and $47.2 \%$ for RP1 data sets. For the last one $20.6 \%$ of the results do not describe correctly the direction of the transport. The values of $\theta_{c r}$ were computed from Soulsby (1997) except for the rippled bed tests of Watanabe and Isobe, where $\theta_{c r}$ was set equal to 0.11 for $d_{50}=0.18 \mathrm{~mm}$ and 0.06 for the $d_{50}=0.87 \mathrm{~mm}$, according to the Watanabe and Isobe (1990). For these conditions the equivalent roughness was computed by taking into account only the grain and transport contributions. The inclusion of the form drag component in rippled beds led to an overestimation of net transport rates.

The major improvements observed with the newly formulated model are seen concerning the steady current test cases: the percentage of computed values within a factor of 2 is $73.3 \%$, $98.3 \%$ and $100 \%$ for the VOG1, VOG2 (both with dune type forms) and ND test cases (flat bed), respectively. However, the numerical solutions obtained in VOG1 and VOG2 tests depend on the roughness specified for the dune bed forms. The solutions shown in Fig. 13a and b considered a constant $K_{s}=60 \mathrm{~cm}$. This corresponds to the maximum roughness that would occur for tidal peak velocities of the order of $1.7 \mathrm{~m} / \mathrm{s}$.

\section{Application of the new semi-unsteady model to regular and irregular skewed waves}

In order to test and verify the sand transport formula proposed on the case of skewed waves, three sets of experimental data were considered, as presented in Table 2.

The King (1991) data set - KG - refers to a series of laboratory experiments performed in the oscillatory flow tunnel of the Hydraulics Laboratory at Scripps Institute of Oceanography under half sawtooth waves. The bed load transport was measured considering two mirror waveforms: one with a steep front and gradual rear and the other with a gradual front and steep rear. The wave period and maximum velocity were kept constant for each pair of mirror waveforms. Three kinds of sediment median diameters were used in the experiments: $0.135 ; 0.44$ and $1.1 \mathrm{~mm}$. The experimental results obtained

Table 2

Skewed waves data set

\begin{tabular}{lllllll}
\hline & $\begin{array}{l}\text { Flow } \\
\text { condition }\end{array}$ & $\begin{array}{l}\text { Regime } \\
\theta_{s}\end{array}$ & $\begin{array}{l}\text { Range of } \\
\theta_{50} \\
(\mathrm{~mm})\end{array}$ & $\begin{array}{l}n^{\circ} \\
\text { tests }\end{array}$ & Reference \\
\hline KG & $\begin{array}{l}\text { Half } \\
\text { sawtooth }\end{array}$ & sf & - & $0.135 ;$ & 52 & King (1991) \\
DW98 & $\begin{array}{l}\text { Irregular } \\
\text { waves }\end{array}$ & sf & $0.5-1.1$ & 0.20 & 28 & $\begin{array}{l}\text { Dibajnia and } \\
\text { Watanabe (1998) }\end{array}$ \\
WS04 & $\begin{array}{l}\text { Sawtooth } \\
\text { waves }\end{array}$ & sf & $0.7-4.0$ & $0.20 ;$ & 52 & $\begin{array}{l}\text { Watanabe and Sato } \\
(2004)\end{array}$ \\
\hline
\end{tabular}

Note. $s f$ - sheet flow. 


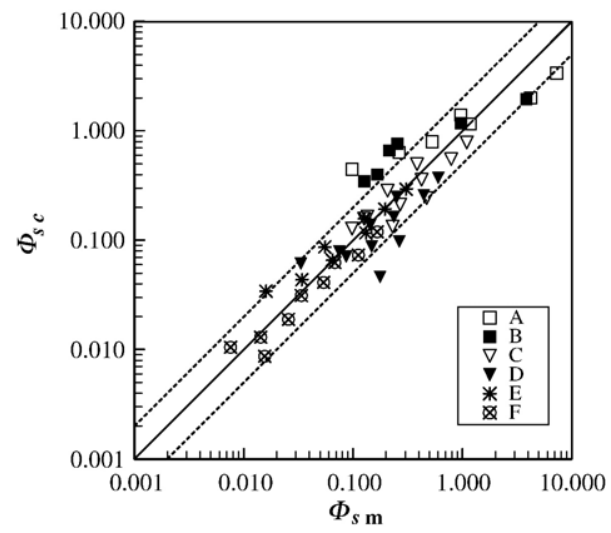

Fig. 14. Measured against predicted dimensionless net transport rates for the King data set $\left(d_{50}=0.135 \mathrm{~mm}\right.$ : A - steep front, B - steep rear; $d_{50}=0.44 \mathrm{~mm}$ : $\mathrm{C}$ - steep front, $\mathrm{D}-$ steep rear; $d_{50}=1.1 \mathrm{~mm}$ : $\mathrm{E}-$ steep front, $\mathrm{F}-$ steep rear).

show that when the same asymmetry waveform is considered in the forward and reversed direction different amounts of transport occur: the waveforms with a steep front transport more sediment than the ones with a steep rear.

For the purposes of calculating the sediment transport rate with the new proposed formula we have considered that the signal imposed in the oscillatory flow tunnel can be approximated by the waveform depicted in Fig. 3 with a value for $s_{k}$ equal to 0.22 for the steep front and 0.78 for the steep rear. Fig. 14 compares the computed and measured values of the dimensionless transport, respectively, $\Phi_{s c}$ and $\Phi_{s m}$. The percentage of computed values within a factor of 2 is $82.6 \%$. The main differences arise concerning the experimental conditions performed with the finest sediment.

The Dibajnia and Watanabe (1998) experiments - DW98 have been conducted in sheet flow conditions in the OWT of University of Tokyo. The velocity time series generated in the OWT was obtained by measuring the near bottom velocities of shoaling irregular waves (corresponding to two types of power spectrum) over a uniform slope in a wave flume. The significant values (one-third) of the total velocity amplitude, wave period, maximum velocity under the wave crest and $T_{p c}$ are known and

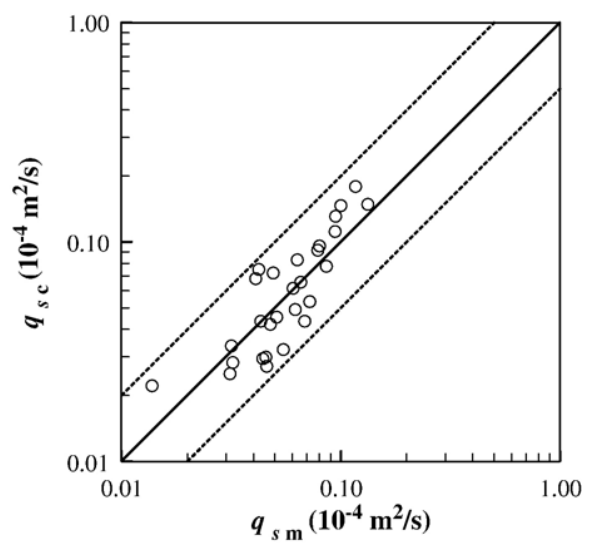

Fig. 15. Measured against predicted net transport rates for the Dibajnia and Watanabe (1998) data set.

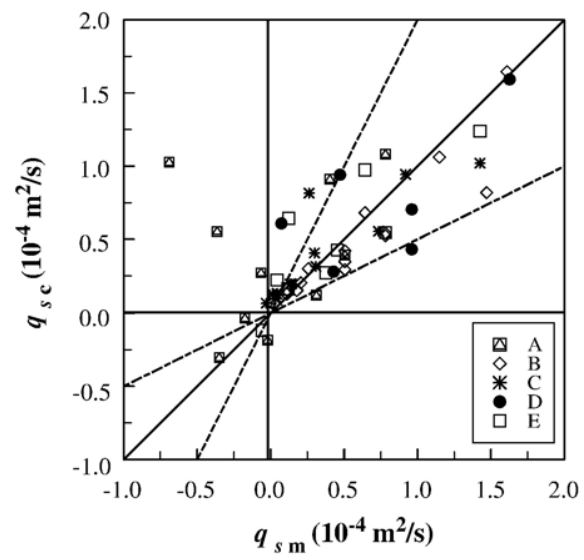

Fig. 16. Measured against predicted net transport rates for the Watanabe and Sato data set $\left(\mathrm{A}-d_{50}=0.2 \mathrm{~mm}, T=3 \mathrm{~s}, U_{0}=-0.2 \mathrm{~m} / \mathrm{s} ; \mathrm{B}-d_{50}=0.2 \mathrm{~mm}\right.$, $T=3 \mathrm{~s}, U_{0}=0 ; \mathrm{C}-d_{50}=0.2 \mathrm{~mm}, T=5 \mathrm{~s}, U_{0}=0, \mathrm{D}-d_{50}=0.74 \mathrm{~mm}, T=3 \mathrm{~s}$, $U_{0}=0 ; \mathrm{E}-d_{50}=0.2 \mathrm{~mm}, T=3 \mathrm{~s}, U_{0}=-0.1 \mathrm{~m} / \mathrm{s}$ ).

were computed from the analysis made of the irregular velocity time series. In the computations performed with the new formula, two types of representative waves were considered: a 2nd order Stokes wave and a sinus wave. For each test condition, the parameters of the representative wave (including its skewness) were computed in terms of the significant values because, as stated by Dibajnia and Watanabe (1998), sediment is supposed to be transported mainly by the larger velocities. The results obtained for the sediment transport rate are compared with the measurements in Fig. 15 for the case of a sinus representative wave. It is evident that the computed values agree well to the measured values. When a 2nd order Stokes wave was considered (not shown), the computed values of $q_{s}$ for 6 test conditions exceeded the factor 2 .

The experiments reported by Watanabe and Sato (2004) WS04 - were performed in the University of Tokyo OWT with oscillatory regular flow with asymmetric acceleration and $\overline{u^{3}}=$ 0 with or without a steady flow. Net sediment transport rates were evaluated for 52 cases corresponding to different values of acceleration asymmetry, wave velocity amplitude, $d_{50}$, and wave period. This data set is unique for testing the performance of sediment transport models because transport is exclusively due to acceleration effects: any transport model that disregards this process gives zero net transport rates.

Fig. 16 compares the computed and measured net transport rates. The numerical results were obtained considering a sinus wave and the asymmetry was taken into account from the known values of $T_{p c}$ and $T_{p t}$. Other numerical experiments, where the velocity time series was derived by assuming that the acceleration is similar to the velocity of a first-order cnoidal wave, gave similar results and are not presented herein. The numerical results are satisfactory, except for the wave plus current $(-0.2 \mathrm{~m} / \mathrm{s})$ experimental cases. For the 52 tests, $67.3 \%$ are within the factor 2. A detailed analysis of the numerical results revealed that there is an important exchange of sediment between the 2 nd and the 1 st half cycles, especially for the cases with strong asymmetry. Neglecting this process does not lead to reasonable results. 


\section{Conclusions}

The sediment transport models to be used in morphodynamic calculations should include simple time saving methodologies and at the same time describe some of the main processes that are necessary for an accurate description of sediment transport in coastal zones, despite its complexity. The present work aims to contribute towards the achievement of such a purpose.

The practical formula presented is based on the work of Dibajnia and Watanabe (1992), whose originality, was to parameterize the unsteady effects in sediment transport in terms of a delayed settling time of sediment particles. The newly proposed practical formula extends the approach of D\&W to more general flow conditions (non collinear wave-current flows and steady flows), taking into account the non-linear and asymmetric characteristics of waves, which are important features as waves approach the shore. Some of the limitations of the original formulation, namely, its bad performance with respect to the effect of the sediment grain size have been overcome. The evaluation of net sediment transport rates as a function of the equivalent Shields parameter was revealed to be satisfactory enough to reproduce the acceleration effects in skewed waves and the experimental results in steady flow conditions. We have also parameterized the characteristic variables of the model, the equivalent sinusoidal velocities and times of duration of each half cycle in an oscillatory flow, in terms of the usual wave and current parameters and have established formulas for nonsteady effects (Eq. (56)) that can be easily incorporated in other quasi-steady formulations.

The new proposed semi-unsteady model can be viewed as an adaptation of the Meyer-Peter and Müller formula to oscillatory flows. In fact, the half cycle average dimensionless transport rate in collinear wave-current flows, disregarding the unsteady effects, is from Eqs. (15), (21) and (61) equal to $3.2\left(\theta_{i}-\theta_{c r}\right)^{1.65}$. Furthermore, this result agrees with the result obtained by Nielsen (1992) (see Equation 2.4.2 and Figure 2.4.2 therein).

Verification of this formulation was carried out using a large data set of experimental results (430 tests) and a good agreement between the computations and measurements was found. For wave and combined wave-current flows in sheet flow and rippled bed conditions the computed values within a factor of 2 are $95 \%$ and nearly $50 \%$, respectively; for sawtooth waves in sheet flow regime the percentage of computed values within a factor of 2 is also quite satisfactory, $83 \%$ for the $\mathrm{KG}$ data set, $100 \%$ for the irregular skewed waves of DW98 and $67.3 \%$ for the WS04. Finally, for the steady current tests we have obtained $73.3 \%, 98.3 \%$ and $100 \%$ of the cases within the factor of 2 for the VOG1, VOG2 (both with dune type forms) and ND (flat bed) tests, respectively. The values of $d_{50}$ for the ensemble of the data sets range from very fine sands $(0.13 \mathrm{~mm})$ up to coarser $1 \mathrm{~mm}$ sand and the values of the skin Shields parameter, $\theta_{s}$, between 0.08 and 4 .

The large discrepancy is observed concerning the rippled bed tests. Further research on this topic is needed, because only the data set of Watanabe and Isobe (1990) was considered to make comparisons. Sensitivity tests have shown that the computed values of net sediment transport depend on the formula used to evaluate the wave friction factor, $f_{\mathrm{w}}$, on the specified roughness and on the critical value of the Shields parameter.

In the literature one can find practical sediment transport formulas that also take into account the acceleration asymmetry in waves (Drake and Calantoni, 2001, Nielsen and Callaghan, 2003; Watanabe and Sato, 2004). Drake and Calantoni (2001) have extended the bed load transport equation of Bailard with a single acceleration term that takes into account acceleration skewness. In Nielsen and Callaghan (2003) (see also Nielsen, 1992), the sediment transport rates are calculated from the Meyer-Peter and Müller formula and take into account both streaming and acceleration asymmetry in the bed shear stress. Watanabe and Sato (2004) proposed a formula based on the early works of Dibajnia and Watanabe $(1992,2001)$. The sediment transport rates are calculated from the velocities amplitudes $u_{c}$ and $u_{t}$, referred to in Eq. (1), modified by an acceleration asymmetry index. The former two models are not recommended for rippled beds and sheet flow of fine sediment because they are quasi-steady formulas. The model of Watanabe and Sato (2004) gave similar results as the ones presented here for the Watanabe and Sato (2004) data set. However, this formula calculates the net transport rates in terms of the equivalent velocity amplitudes and this limits the extent to which the model can be applied to steady dominating flows. Therefore, it is our understanding that the proposed semi-unsteady model can be applied on a wider basis, as has been shown from the results obtained.

All the oscillatory flow experimental data considered in this study were obtained in OWT. The net transport rates measured by Ribberink et al. (2000) for real progressive waves in a wave flume are approximately a factor of 2 larger than in similar sediment transport measurements in the OWT. According to these authors and Nielsen and Callaghan (2003), this disparity is partially due to the presence of boundary layer streaming, which is absent in the OWT flows (Ribberink and Al-Salem, 1994). Thus, the application of the present model to real progressive waves requires an estimation of the boundary layer streaming effects on sediment transport (see Nielsen and Callaghan, 2003) or, alternatively, an estimation of the streaming velocity.

Application of the present practical formula to non-collinear wave-current flows is presented in Silva et al. (2005); the results are encouraging.

\section{Acknowledgments}

The work was carried out as part of the SEDMOC EU MASTIII (Project No. MAS3-CT97-0115) and SANDPIT (EVK3-CT-2001-00056) project. The authors are indebted to Akira Watanabe and Shinji Sato for providing their experimental data and to the referees of the journal for their invaluable comments.

\section{References}

Ahmed, A.S.M., Sato, S., 2003. A sheet flow transport model for asymmetric oscillatory flows, Part I. Coast. Eng. J. 45 (3), 321-337.

Bailard, J.A., 1981. An energetic total load sediment transport model for a plane sloping beach. J. Geophys. Res. 86 (C11), 10938-10954. 
Damgaard, J.S., van Rijn, L.C., Hall, L.J., Soulsby, R.L., 2001. Intercomparison of engineering methods for sand transport. In: van Rijn, L.C., Davies, A.G., van de Graaff, J., Ribberink, J.S. (Eds.), SEDMOC-Sediment transport modelling in marine coastal environments. Aqua Publications, The Netherlands, pp. 1-12.

Davies, A.G., Ribberink, J.S., Temperville, A., Zyzerman, J.A., 1997. Comparisons between sediment transport models and observations made in wave and current flows above plane beds. Coast. Eng. 31, 163-198.

Davies, A.G., van Rijn, L.C., Damgaard, J.S., van de Graaff, J., Ribberink, J.S., 2002. Intercomparison of research and practical sand transport models. Coast. Eng. 46, 1-23.

Dibajnia, M., 1995. Sheet flow transport formula extended and applied to horizontal plane problems. Coast. Eng. Jpn., JSCE 38 (2), 179-194.

Dibajnia, M., Watanabe, A., 1992. Sheet flow under non-linear waves and currents. Proc. 23rd Int. Conf. on Coastal Eng. pp. 2015-2028.

Dibajnia, M., Watanabe, A., 1996. A transport rate formula for mixed-size sands. Proc. 25th Int. Conf. on Coastal Eng. pp. 3791-3804.

Dibajnia, M., Watanabe, A., 1998. Transport rate under irregular sheet flow conditions. Coast. Eng. 35, 167-183.

Dibajnia, M., Watanabe, A., 2001. A representative wave model for estimation of nearshore local transport rate. Coast. Eng. J. 43 (1), 1-38.

Dohmen-Janssen, C.M., 1999. Grain size influence on sediment transport in oscillatory sheet flow. Ph.D. Thesis, Delft University of Technology, The Netherlands.

Dohmen-Janssen, C.M., Kroekenstoel, D.F., Hassan, W.N., Ribberink, J.S., 2002. Phase lags in oscillatory sheet flow: experiments and bed load modelling. Coast. Eng. 46, 61-87.

Drake, T.G., Calantoni, J., 2001. Discrete particle model for sheet flow sediment transport in the nearshore. J. Geophys. Res., [Oceans] 106 (C9), 19859-19868

Elgar, S., Gallagher, E.L., Guza, R.T., 2001. Nearshore sandbar migration. J. Geophys. Res., [Oceans] 106 (C6), 11623-11627.

Guizien, K., Temperville, A., 1999. Bottom shear stress under a linear irregular wave. C. R. Acad. Sci. Ser. II. Fasc. B 327 (14), 1375-1378

Guizien, K., Silva, P.A., Seabra Santos, F., 2001. Mathematical modelling of sand transport by combined waves and currents in the sheet flow regime using RANS turbulence models; hindering and flow reversal ejections. In: van Rijn, L.C., Davies, A.G., van de Graaff, J., Ribberink, J.S. (Eds.), SEDMOC-Sediment transport modelling in marine coastal environments. Aqua Publications, The Netherlands, BD, pp. 1-8.

Guizien, K., Dohmen-Janssen, C.M., Vittori, G., 2003. 1DV bottom boundary layer modeling under combined wave and current: Turbulent separation and phase lag effects. J. Geophys. Res. 108 (C1) (Art. No. 3016).

Hassan, W., 2003. Transport of size-graded and uniform sediments under oscillatory sheet-flow conditions. Ph.D. Thesis, University of Twente, The Netherlands.

Huynh Thanh, S., Tran Thu, T., Temperville, A., 1994. A numerical model for suspended sediment in combined currents and waves. Euromech, vol. 310 World Scientific, pp. 122-130.

Janssen, C.M., Riberrink, J.S., 1996. Influence of grain diameter on sand transport in oscillatory sheet flow. Proc. 25th Int. Conf. on Coastal Eng. pp. 4779-4792.

Katopodi, I., Ribberink, J.S., Ruol, P., Koelewijn, R., Lodahl, C., Longo, S., Crosato, A., Wallace, H., 1994. Intra-wave sediment transport in an oscillatory flow superimposed on a mean current. Data report H 1684, Part III. Delft Hydraulics.

King. B., 1991. Studies in oscillatory flow bed load sediment transport. Ph.D thesis, University of California, San Diego.

Koelewijn, H., Ribberink, J.S., 1994. Sediment transport under sheet flow conditions. Delft University of Technology, Department of Civil Engineering, WL $\mid$ Delft Hydraulics.

Madsen, O.S., Grant, W.D., 1976. Quantitative description of sediment transport by waves. 15th Int. Conf. on Coastal Eng. pp. 1093-1112.
Nielsen, P., 1979. Some basic concepts of wave sediment transport. Inst. of Hydrodyn. and Hydr. Eng. Tech. Univ. Denmark, series paper, vol. 20.

Nielsen, P., 1992. Coastal bottom boundary layers and sediment transport. Advanced Series on Coastal Eng., vol. 4. World Scientific Pub.

Nielsen, P., Callaghan, D.P., 2003. Shear stress and sediment transport calculations for sheet flow under waves. Coast. Eng. 47, 347-354.

Nnadi, F., Wilson, K., 1992. Motion of contact - load particles at high shear stress. J. Hydrol. Eng. 118 (12), 1670-1684.

O'Donoghue, T., Wright, S., 2004. Flow tunnel measurements of velocities and sand flux in oscillatory sheet flow for well-sorted and graded sands. Coast. Eng. 51, 1163-1184.

Ribberink, J.S., 1998. Bed-load transport for steady flows and unsteady oscillatory flows. Coast. Eng. 34, 59-82.

Ribberink, J.S., Al-Salem, A., 1994. Sediment transport in oscillatory boundary layers in cases of rippled bed and sheet flow. J. Geophys. Res. 99 (C6), 12707-12727.

Ribberink, J.S., Chen, Z., 1993. Sediment transport of fine sand under asymmetric oscillatory flow. Rep. H840, Part VII. Delft Hydraulics, The Netherlands.

Ribberink, J.S., Dohmen-Janssen, C.M., Hanes, D.M., McLean, S.R., Vincent, C., 2000. Near-bed transport mechanisms under waves. A large-scale flume experiments (Sistex99). 27th Int. Conf. on Coastal Eng. pp. 3263-3276.

Savioli, J., Justesen, P., 1997. Sediment in oscillatory flows over a plane bed. J. Hydraul. Res. 35 (2), 177-190.

Sawamoto, S., Yamashita, T., 1986. Sediment transport rate due to wave action. J. Hydrosci. Hydraul. Eng. 4 (1), 1-15.

Silva, P.A., 2001. Contribution to the study of sediments dynamics in coastal zones. Ph.D. Thesis, University of Aveiro, Portugal. [in Portuguese].

Silva, P.A., Temperville, A., 2000. Prediction of sediment transport with the Dibajnia and Watanabe formula. Proc. Vièmes Journées Nationales Génie Civil-Génie Côtier, Caen, France, pp. 237-248. in French.

Silva, P.A., Temperville, A., Seabra Santos, F.J., 2001. Parameterized sand transport model for combined currents and waves in rippled and flat bed regimes. In: Van Rijn, L.C., Davies, A.G., Van de Graaff, J., Ribberink, J.S. (Eds.), SEDMOCSediment transport modelling in marine coastal environments. Aqua Publications, The Netherlands. ISBN: 90-800356-4-5, CE 1-10.

Silva, P.A., Temperville, A., Guizien, K., 2005. Sand transport in combined steady and oscillatory flow: non steady processes, skewed waves and ripple beds. In: van Rijn, L.C., Soulsby, R.L., Hoekstra, P., Davies, A.G. (Eds.), SANDPIT - Sand Transport and Morphology of Offshore Sand Mining Pits. Aqua Publications, The Netherlands. ISBN: 90-800356-7-X, AF 1-9.

Soulsby, R.L., 1997. Dynamics of marine sands. Thomas Telford Publications, London.

Soulsby, R.L., Hamm, L., Klopman, G., Myrhaug, D., Simons, R., Thomas, G., 1993. Wave-current interaction within and outside the bottom boundary layer. Coast. Eng. 21 (1-3), 41-69.

Swart, D.H., 1974. Offshore sediment transport and equilibrium beach profiles. Delft Hydr. Lab., Publ., vol. 131. Delft Hydraulics, The Netherlands.

Tran Thu, T., 1995. Numerical modelling of the wave-current-sediment interaction, Ph.D. Thesis, University of Joseph Fourier, Grenoble. [in French].

van Rijn, L.C., 1984. Sediment transport, Part III: bed forms and alluvial roughness. J. Hydrol. Eng. 110 (12), 1733-1754.

Voogt, L., van Rijn, L.C., van den Berg, J.H., 1991. Sediment transport of fine sands at high velocities. J. Hydrol. Eng. 117 (7), 869-890.

Watanabe, A., Isobe, M., 1990. Sand transport rate under wave-current action. Proc. 22nd Int. Conf. on Coastal Eng. pp. 2495-2507.

Watanabe, A., Sato, S., 2004. A sheet-flow transport rate formula for asymmetric, forward-leaning waves and currents. Proc. 29th Int. Conf. on Coastal Eng. , pp. 1703-1714.

Wilson, K.C., 1989. Friction of wave induced sheet flow. Coast. Eng. 12, $371-379$. 